Federal Reserve Bank of Minneapolis

Research Department Staff Report 239

September 1997

\title{
Capital-Skill Complementarity and Inequality: A Macroeconomic Analysis
}

\author{
Per Krusell* \\ University of Rochester \\ and Institute for International Economic Studies
}

\author{
Lee E. Ohanian* \\ University of Minnesota \\ and Federal Reserve Bank of Minneapolis
}

José-Víctor Ríos-Rull*

Federal Reserve Bank of Minneapolis

and University of Pennsylvania

Giovanni L. Violante

University College, London

\begin{abstract}
The notion of skilled-biased technological change is often held responsible for the recent behavior of the U.S. skill premium, or the ratio between the wages of skilled and unskilled labor. This paper develops a framework for understanding this notion in terms of observable variables and uses the framework to evaluate the fraction of the skill premium's variation that is caused by changes in observables. A version of the neoclassical growth model is used in which the key feature of aggregate technology is capital-skill complementarity: the elasticity of substitution is higher between capital equipment and unskilled labor than between capital equipment and skilled labor. With this feature, changes in observables can account for nearly all the variation in the skill premium over the last 30 years. This finding suggests that increased wage inequality results from economic growth driven by new, efficient technologies embodied in capital equipment.
\end{abstract}

*Krusell, Ohanian, and Ríos-Rull thank the National Science Foundation. The views expressed herein are those of the authors and not necessarily those of the Federal Reserve Bank of Minneapolis or the Federal Reserve System. 


\section{Introduction}

There have been striking changes in the quantity and price of skilled labor relative to unskilled labor over the postwar period. For education-based skill classifications, the quantity of skilled labor relative to unskilled labor has increased considerably, and the skill premium, defined as the wage of skilled labor relative to unskilled labor, has grown significantly since 1980. Perhaps the most widely studied question about these observations is: Why has the skill premium risen during a period of substantial growth in the relative supply of skilled labor? Many studies have found that it is difficult to account for the increase in the skill premium on the basis of observable variables and have concluded that latent skill-biased technological change is the main factor responsible for the increase. ${ }^{1}$ However, there is no generally accepted, explicit economic mechanism for interpreting skill-biased technological change, nor are there any direct measures of the implicit trend growth in this object.

In this paper, we develop a theoretical framework that provides a simple, explicit economic mechanism for understanding the importance of skill-biased technological change in terms of observable variables, and we use the framework to evaluate the fraction of historical variation in the skill premium that can be accounted for by changes in observed factor quantities and the fraction that is due to unobserved variables. We conduct our analysis using a version of the neoclassical growth model in which the key feature of the aggregate technology is capital-skill complementarity. In our framework, this means that the elasticity of substitution between capital equipment and unskilled labor is higher than that between capital equipment and skilled labor. An important implication of capital-skill complementarity is that growth in the stock of equipment tends to increase the marginal product of skilled labor, but decreases the marginal product of unskilled labor. We hypothesize that capital-skill complementarity may be important for understanding wage inequality because the stock of equipment has been growing at about twice the rate of either capital structures or consumption over much of the postwar period, and its relative price has been falling. Moreover, these trends have accelerated since the late 1970s, a period in which the skill premium has grown substantially. Thus, skill-biased technological change in our framework simply reflects the rapid growth of the stock of capital equipment combined with the different ways that equipment interacts with skilled and unskilled labor in the production technology. 
This hypothesis of capital-skill complementarity is formalized by Griliches (1969). To illustrate how this mechanism can affect the skill premium, consider a three-factor production function similar to one used by Stokey (1996) in a study of inequality and trade. Output is produced with capital equipment $(k)$, unskilled labor $(u)$, and skilled labor $(s)$. Equipment and unskilled labor are perfect substitutes and have unit elasticity of substitution with skilled labor $(s)$ :

$$
y_{t}=f\left(k_{t}, u_{t}, s_{t}\right)=\left(k_{t}+u_{t}\right)^{\theta} s_{t}^{1-\theta} .
$$

The ratio of the marginal product of skilled labor to the marginal product of unskilled labor is

$$
\frac{f_{s_{t}}}{f_{u_{t}}}=\left(\frac{1-\theta}{\theta}\right) \frac{k_{t}+u_{t}}{s_{t}}
$$

This example shows clearly that growth in the stock of equipment, ceteris paribus, will increase the skill premium, since increases in the capital stock increase the marginal product of skilled labor, but will decrease the marginal product of unskilled labor. This example also shows that, with competitive markets and a growing capital stock, increased wage inequality can be a consequence of capital-skill complementarity.

This example is qualitative. Our purpose, however, is to evaluate whether capital-skill complementarity has been a quantitatively important factor in accounting for changes in aggregate wage inequality over the last 30 years. To conduct our quantitative analysis, we use the basic framework of the neoclassical growth model. Given our focus on the connection between capital equipment and wage inequality, we must modify the standard two-factor (aggregate capital and aggregate labor) neoclassical aggregate production function. To do this, we develop a four-factor aggregate production function that explicitly distinguishes between capital equipment, capital structures, skilled labor, and unskilled labor and that allows for different elasticities of substitution between unskilled labor and capital equipment and between skilled labor and capital equipment. With competitive markets, we can simply read factor prices off the value of marginal product schedules of this aggregate production function, and we can then compare the skill premium in the model with the skill premium in the data.

The values of the production function parameters that govern the substitution elasticities 
between capital equipment and skilled labor and between capital equipment and unskilled labor are important elements of this quantitative analysis. We first review elasticity estimates from the existing literature. Although there are no estimates of substitution elasticities between equipment and skilled labor or between equipment and unskilled labor in the literature, there are estimates for these two elasticities using total capital (capital equipment plus structures). These estimates are consistent with capital-skill complementarity. As a starting point for our quantitative analysis, we use these existing elasticity estimates based on total capital as proxies for the elasticities in our model involving equipment, and we compute the skill premium from our model. To assess the importance of capital-skill complementarity, we compare the skill premium from this model with the skill premium from a version of our model with no capital-skill complementarity. This comparison suggests that capital-skill complementarity is a key factor in understanding changes in wage inequality, as the model with capital-skill complementarity accounts for much of the historical variation in the skill premium, while the version without capital-skill complementarity predicts a strongly counterfactual 45 percent decline in the skill premium. We then extend the analysis by estimating the substitution elasticities directly and by evaluating the extent to which the estimated production function is consistent not only with historical variation in the skill premium, but also with other important long-run growth observations. The elasticities that we estimate are very similar to those that we use from the literature.

Our main finding is that with capital-skill complementarity, changes in observed factor inputs alone can account for most of the variation in the skill premium over the last 30 years. During this period, the skill premium has three distinct patterns: a modest increase in the 1960s, a decline over much of the 1970s, and a sharp increase after 1980. The prediction of our simple model with capitalskill complementarity, but no changes in unobserved variables, is consistent with these three key patterns. We also find that our aggregate production function preserves the success of the standard two-factor neoclassical model in that it is consistent with the behavior of income shares and the returns on capital over time. Since the introduction of capital-skill complementarity eliminates the importance of unmeasured trend changes in accounting for the skill premium, we conclude that capital-skill complementarity is a reasonable, explicit economic mechanism for understanding the phenomenon of skill-biased technological change widely cited in the literature.

The paper is organized as follows: In Section 2, we discuss the factor price and quantity 
data we use in the analysis. In Section 3, we present the basic model. In Section 4, we present our quantitative analysis. In Section 5, we provide a summary and conclusion. We discuss the construction of the data and the econometric technique in the appendices.

\section{The Data}

Here, we summarize historical changes in the quantities and prices of capital equipment, structures, skilled labor input, and unskilled labor input. We first document changes in prices and quantities of the two types of capital input. There are large differences in the growth rates of capital equipment and capital structures. Based on the accounting in Gordon (1990) for increases in the efficiency of new capital equipment, the stock of equipment grew at an average rate of about 6.2 percent between 1954 and $1975 .^{2}$ This growth rate increased after 1975, rising to about 7.5 percent per year. Structures, however, grew at a much slower rate between 1954 and 1994, with an average annual increase of 3.2 percent per year. In contrast to the growth rate of equipment, the growth rate of structures slowed after 1975, falling to about 2.6 percent per year. These series are shown in Figure 1. There are also important differences in changes in the relative prices of equipment and structures. Since 1954, the relative price of equipment (to consumption of nondurables and services) fell significantly, declining at an average rate of about 4.5 percent per year, while the relative price of structures (to consumption of nondurables and services) remained roughly constant over this period. Figure 2 shows the decline in the ratio between the Gordon-based price index for capital equipment and the price index for consumption of nondurables and services. ${ }^{3}$ The rate of decline in the relative price of equipment accelerated after 1975, declining at a rate over 6 percent annually. We follow Greenwood, Hercowitz, and Krusell (1996) in interpreting this long-run decline in the relative price of capital as reflecting technological change that is specific to the production of capital equipment.

The literature that has analyzed skilled and unskilled labor generally defines labor skill on the basis of education. Many education measures show a strong secular increase in the quantity of skilled labor relative to the quantity of unskilled labor. Figure 3 shows the ratio of (weighted) hours worked of skilled to unskilled labor. Skilled labor is defined as requiring college completion or better (at least 16 years of school). The data are drawn from the Current Population Survey (CPS) over 
the 1963-92 period. (A detailed description of these data is in Appendix 1.) The principal feature of these data is a substantial increase in the ratio of skilled to unskilled labor input. This ratio rises by more than 100 percent. ${ }^{4}$ Despite the relative increase in the quantity of skilled labor, the wage of skilled labor relative to unskilled labor has increased. Figure 4 shows the three key patterns of the skill premium: a modest increase in the 1960s, a decline over much of the 1970s, and a sharp increase after 1980. Overall, the skill premium increased about 18 percent over the period.

Despite these strong trends in relative input levels and factor prices, the shares of income earned by aggregate capital and aggregate labor have been roughly constant. The aggregate labor share of income is shown in Figure 5. It is defined as the ratio of labor income- defined as wages, salaries, and benefits - to the sum of labor income plus capital income - defined as depreciation, corporate profits, net interest, and rental income of persons. The labor share of income averaged 71 percent over the 1963-92 period, attaining a maximum of about 73 percent in 1970 and a minimum of about 69 percent in 1984 .

In addition to the quantities and prices of these four inputs, we find that the ratio of capital equipment to skilled labor input is important in our analysis. As we discuss in the following section, this ratio affects the skill premium through capital-skill complementarity. Figure 6 presents the ratio of equipment to skilled labor input. This ratio has grown consistently over the entire period, and its growth rate is somewhat higher in the latter part of the period.

To summarize, the main descriptive features of these data are (1) rapid growth in the stock of capital equipment (and a corresponding fall in its relative price) with an acceleration in both trends after 1975, (2) a substantial increase in the relative quantity of skilled labor input, (3) a sharp increase in the skill premium beginning in 1980, (4) an increase in the ratio of capital equipment to skilled labor input, and (5) relative constancy of aggregate income shares of capital and labor.

\section{The Model}

We can simplify our analysis considerably by abstracting from modeling the household sector and focusing on just the aggregate production function. Our basic approach is as follows: We develop a four-factor production function, and then we choose values for the production function parameters. Given the time series of the quantities of the four inputs and the value of marginal 
product schedules from the production function, the model yields factor prices. We define the skill premium in our model as the ratio of the wage of skilled labor to the wage of unskilled labor per unit of work. Thus, we form the ratio of the marginal product of skilled labor to that of unskilled labor from our model, and we can compare the skill premium predicted by the model with that in the data.

We construct our production function by modifying the standard two-factor (aggregate capital and aggregate labor) neoclassical production function commonly used in macroeconomic analysis. There are two key differences between the standard production function and that developed here. One is that we include four factors of production: (1) skilled labor, (2) unskilled labor, (3) capital equipment, and (4) capital structures. We explicitly distinguish between capital equipment and structures because of the very different growth rates of the quantities and relative prices of these variables summarized in the previous section. The other difference is that we allow for different substitution possibilities between skilled labor and equipment and between unskilled labor and equipment.

\section{A A Two-Sector Economy}

Since we interpret the decline in the relative price of capital as equipment-specific technological change, we analyze an economy with two sectors: one produces consumption goods and capital structures and the other produces capital equipment. Output of these two sectors is given by

$$
\begin{gathered}
c_{t}+x_{s t}=A_{t} G\left(k_{s t}^{c}, k_{e t}^{c}, u_{t}^{c}, s_{t}^{c}\right) \\
x_{e t}=q_{t} A_{t} G\left(k_{s t}^{e}, k_{e t}^{e}, u_{t}^{e}, s_{t}^{e}\right)
\end{gathered}
$$

where $c_{t}$ is consumption, $x_{s t}$ is investment in structures, and $x_{e t}$ is output of the equipment sector. The superscripts of the input variables denote the sector in which they are used: $c$ for consumption and structures, $e$ for equipment. Services of capital structures and equipment, $k_{s t}$ and $k_{e t}$, are assumed to be proportional to their respective stocks, which are measured in efficiency units. There are two types of labor input, $u_{t}$ and $s_{t}$, where $u_{t}$ is unskilled labor and $s_{t}$ is skilled labor, again, both measured in efficiency units. There is a common, or neutral, technology factor, $A_{t}$, and another 
technology factor, $q_{t}$, which is specific to the capital equipment sector. The function $G$ is common to both sectors and is homogeneous of degree one. These properties guarantee that under perfect competition in factor markets, profit-maximizing firms will allocate the inputs so that input ratios will be equalized across both sectors. Therefore, the equilibrium relative price between consumption and equipment will equal $q_{t}$ at each point in time. ${ }^{5}$ This allows us to aggregate the sectors by defining total output, $y_{t}$, in consumption units, as

$$
y_{t}=c_{t}+x_{s t}+\frac{x_{e t}}{q_{t}}=A_{t} G\left(k_{s t}, k_{e t}, u_{t}, s_{t}\right)
$$

where the inputs are now defined as the sum of the inputs in each of the two sectors. The evolution of the two stocks of capital is standard, although we allow for type-specific depreciation rates:

$$
\begin{aligned}
& k_{s, t+1}=\left(1-\delta_{s}\right) k_{s t}+x_{s t} \\
& k_{e, t+1}=\left(1-\delta_{e}\right) k_{e t}+x_{e t} .
\end{aligned}
$$

\section{B A Functional Form for the Aggregate Production Function}

To conduct our analysis, we must choose a functional form for the production function. Our objective is to work with a parsimoniously parameterized function in the four inputs: $s, u, k_{e}$, and $k_{s}$. Translog production functions offer considerable flexibility, but involve a large number of parameters. Since the CPS data we use to construct skilled and unskilled labor input are annual and begin in 1963, it would be difficult to estimate a translog function. Therefore, we restrict our attention to the class of constant elasticity of substitution (CES) production technologies. This type of production function is tractable, involves considerably fewer parameters than the translog function, is characterized by elasticities of substitution that are constant, and provides a relatively simple specification that allows us to evaluate the role of capital-skill complementarity in accounting for changes in the skill premium in a transparent way.

We simplify the production function by assuming that it is Cobb-Douglas over capital structures and a CES aggregate of the three remaining inputs and that the remaining inputs are nested in a general CES form. Thus, $y=k_{s}^{\alpha} \tilde{y}^{1-\alpha}$, where $\tilde{y}$ is a constant returns to scale CES aggregate of 
$u, k_{s}$, and $k_{e}$.

There are three ways of nesting these inputs within a CES function. Each nesting allows two elasticities of substitution to be different, but restricts the third elasticity by the symmetry of the CES aggregator. The first nesting is $\tilde{y}=\Upsilon_{1}\left(k_{e}, \Upsilon_{2}(s, u)\right)$, where $\Upsilon_{1}$ and $\Upsilon_{2}$ are different CES functions. This formulation, which is used in Katz and Murphy (1992), does not allow for capital-skill complementarity, because it restricts the elasticity of substitution between $k_{e}$ and $u$ be the same as that between $k_{e}$ and $s$. The other two possible nestings do allow for capital-skill complementarity. They are $\tilde{y}=\Upsilon_{1}\left(s, \Upsilon_{2}\left(k_{e}, u\right)\right)$ and $\tilde{y}=\Upsilon_{1}\left(u, \Upsilon_{2}\left(s, k_{e}\right)\right)$. The first of these two specifications restricts the elasticity of substitution between $s$ and $k_{e}$ to be the same as that between $s$ and $u$. However, this restriction is a shortcoming of the first specification, since the literature on factor elasticities suggests that the elasticity of substitution between skilled labor and unskilled labor is higher than the elasticity of substitution between skilled labor and capital. (See Hamermesh (1993).) Perhaps not surprisingly, we also find that this first specification is not as consistent with the data as the second specification. Therefore, we use the second specification in our analysis. ${ }^{6}$ This specification is given by

$$
G\left(k_{s t}, k_{e t}, u_{t}, s_{t}\right)=k_{s t}^{\alpha}\left[\mu u_{t}^{\sigma}+(1-\mu)\left(\lambda k_{e t}^{\rho}+(1-\lambda) s_{t}^{\rho}\right)^{\frac{\sigma}{\rho}}\right]^{\frac{1-\alpha}{\sigma}} .
$$

In this specification, $\mu$ and $\lambda$ are share parameters and $\sigma$ and $\rho$ govern the elasticity of substitution between unskilled labor, capital equipment, and skilled labor. This nested production function also has a symmetry property: the elasticity of substitution between equipment and unskilled labor is the same as that between skilled labor and unskilled labor. In the next section, we show that for the parameter values we ultimately choose that this symmetry property does not restrict any elasticities to be at variance with estimates from the literature. Note that this in contrast to the symmetry restriction embedded in the other nesting described above. With this formulation, the elasticity of substitution between equipment (or skilled labor) and unskilled labor is $\frac{1}{1-\sigma}$, and the elasticity of substitution between equipment and skilled labor is $\frac{1}{1-\rho}$. The case in which capital is more complementary with skilled labor than with unskilled labor corresponds to $\sigma>\rho .^{7}$ To maintain strict quasi-concavity of the production function, both $\sigma$ and $\rho$ are restricted to lie in $(-\infty, 1)$. If either $\sigma$ or $\rho$ equals zero, the corresponding nesting is Cobb-Douglas. Values of $\sigma$ or $\rho$ greater than 
zero indicate greater substitutability than in the Cobb-Douglas case.

The labor input of each type is measured in efficiency units: each input type is a product of the raw number of labor hours and an efficiency index. In particular, $s_{t} \equiv \psi_{s t} h_{s t}$ and $u_{t} \equiv \psi_{u t} h_{u t}$, where $h_{i t}$ is the number of hours worked and $\psi_{i t}$ is the (unmeasured) quality per hour of type $i$ at date $t$. It is clear that $\psi_{i}$ can be given different interpretations: it can be human capital, accumulated by the agent, or it can represent a skill-specific technology level, which may have come about by research and development. In the absence of direct measures of labor quality for each skill level, these two interpretations cannot be distinguished. In the following section, we discuss the exact specification of this unobserved term.

\section{The Skill Premium From the Model}

Following the literature in this area, we define the skill premium, $\pi$, as the ratio of skilled labor wages to unskilled labor wages. Our modification of the standard neoclassical production function has a number of interesting implications for the skill premium. Given our assumption that factor prices are equal to marginal products per unit of work, the skill premium can be expressed as a function of input ratios:

$$
\pi_{t}=\frac{(1-\mu)(1-\lambda)}{\mu}\left[\lambda\left(\frac{k_{e t}}{s_{t}}\right)^{\rho}+(1-\lambda)\right]^{\frac{\sigma-\rho}{\rho}}\left(\frac{h_{u t}}{h_{s t}}\right)^{1-\sigma}\left(\frac{\psi_{s t}}{\psi_{u t}}\right)^{\sigma}
$$

The effects of input ratios are important, since these ratios show significant trends over the postwar period. One effect of capital-skill complementarity on the skill premium can be seen in the first ratio in the expression. When the quantities of the two types of labor inputs are held fixed, the change in the skill premium in response to an increase in the amount of equipment is positive if and only if $\sigma>\rho$. This implies that an increase in the stock of equipment, ceteris paribus, will increase the skill premium only if the elasticity of substitution between equipment and unskilled labor is higher than that between equipment and skilled labor. Another important effect is that for all admissible parameter values, the skill premium is increasing in the ratio of unskilled to skilled labor hours.

To further illustrate the implications of this model for the skill premium, we log-linearize the expressions and decompose the log of the skill premium into three components that have specific 
economic interpretations. Log-linearizing equation (7) and omitting the constant term yields

$$
\ln \pi_{t} \simeq \lambda \frac{\sigma-\rho}{\rho}\left(\frac{k_{e t}}{s_{t}}\right)^{\rho}+(1-\sigma) \ln \left(\frac{h_{u t}}{h_{s t}}\right)+\sigma \ln \left(\frac{\psi_{s t}}{\psi_{u t}}\right)
$$

After differentiating this expression with respect to time and denoting the growth rate of variable $x$ by $g_{x}$, we obtain, after some algebra, ${ }^{8}$

$$
\begin{aligned}
g_{\pi t} \simeq & (1-\sigma)\left(g_{h_{u t}}-g_{h_{s t}}\right)+\sigma\left(g_{\psi_{s t}}-g_{\psi_{u t}}\right) \\
& +(\sigma-\rho) \lambda\left(\frac{k_{e t}}{s_{t}}\right)^{\rho}\left(g_{k_{e t}}-g_{h_{s t}}-g_{\psi_{s t}}\right) .
\end{aligned}
$$

Equation (8) is an important object, since it provides a simple way of using our model to understand how changes in the growth rates of inputs separately affect the growth rate of the skill premium at any point in time. This allows us to isolate the effect of capital-skill complementarity on the skill premium from two other components which are important elements in other studies of the skill premium. The first component, $(1-\sigma)\left(g_{h_{u t}}-g_{h_{s t}}\right)$, depends on the growth rate of skilled labor input relative to the growth rate of unskilled labor input. Following the literature, we call this component the relative quantity effect. Since $\sigma<1$, faster growth of unskilled labor than of skilled labor increases the skill premium.

The second component, $\sigma\left(g_{\psi_{s t}}-g_{\psi_{u t}}\right)$, involves the growth of skilled labor efficiency relative to that of unskilled labor efficiency. We call this component the relative efficiency effect. The effect of a relative increase in the growth rate of skilled labor efficiency on the skill premium depends on $\sigma$, which governs the substitution elasticity between the two labor inputs. If the elasticity of substitution between skilled and unskilled labor is greater than one, a relative improvement in the quality of skilled labor increases the skill premium. However, if there is sufficient complementarity between skilled and unskilled labor, a relative improvement in the efficiency of skilled labor leads to a relative increase in the marginal product of unskilled labor, which results in a decline in the skill premium.

The third component, $(\sigma-\rho) \lambda\left(\frac{k_{e t}}{s_{t}}\right)^{\rho}\left(g_{k_{e t}}-g_{h_{s t}}-g_{\psi_{s t}}\right)$, is the capital-skill complementarity effect. This component depends on two factors: the growth rate of equipment relative to the growth rates of skilled and unskilled labor input, and the ratio of capital equipment to efficiency 
units of skilled labor input. If $\sigma>\rho$, skilled labor is more complementary with equipment than is unskilled labor. In this case, faster growth in equipment tends to increase the skill premium as it

increases the relative demand for skilled labor. To illustrate the effect of $\left(\frac{k_{e t}}{s_{t}}\right)^{\rho}$ on the skill premium, assume that the equipment growth rate exceeds the growth rate of efficiency units of skilled labor. With these assumptions, the growth rate of the skill premium increases over time if $\rho>0$ (more substitutable than Cobb-Douglas) but decreases if $\rho<0$. With $\rho<0$, the share of income paid to equipment relative to the share paid to skilled labor goes to zero in the limit and, as a result, income is divided solely between skilled and unskilled labor. Since the share of income paid to skilled labor is bounded at one, the growth rate of the skill premium is bounded. This is because the wage growth of skilled labor in this limiting case equals growth in total output less growth in skilled labor input. Thus, the effect of this ratio on the growth rate of the skill premium depends on the shape of the isoquants of the technology. ${ }^{9}$

\section{Quantitative Analysis}

\section{A An Initial Analysis of the Importance of Capital-Skill Complementarity}

With values for the parameters of the production function, we can use equation (8) to assess quantitatively how the skill premium has been affected by capital-skill complementarity and by the other two factors derived in the previous section. In this section, we present results from two experiments designed to provide an initial quantitative evaluation of the importance of capital-skill complementarity in accounting for changes in wage inequality. In these experiments, we compare the actual skill premium in the data to the skill premium in the model for particular values of the production function parameters. To focus on the extent to which observable variables can account for changes in the skill premium, we restrict the unmeasured quality of the two types of labor $\left(\psi_{u}\right.$ and $\left.\psi_{s}\right)$ to be constant in these two experiments.

In the first experiment, we use our model to answer the following question: What would have happened to the skill premium between 1963 and 1993 if there were no capital-skill complementarity and no changes in unmeasured labor quality? Thus, this experiment consists of restricting the substitution elasticities between unskilled labor and capital and between skilled labor and capital to be the same. By abstracting from capital-skill complementarity and from unmeasured changes 
in labor quality, this experiment isolates the effects of changes in the relative quantities of the two types of labor on the skill premium. For this first experiment, we work with the following simplified version of our production function:

$$
G\left(k_{t}, u_{t}, s_{t}\right)=k_{e t}^{\alpha}\left[\mu\left(\psi_{u} h_{u t}\right)^{\sigma}+(1-\mu)\left(\psi_{s} h_{s t}\right)^{\sigma}\right]^{\frac{1-\alpha}{\sigma}}
$$

To conduct this experiment, it is necessary to choose values for the production function parameters. The parameter $\alpha$ does not appear in the skill premium expression, and since unmeasured labor quality is assumed to be constant, the terms $\psi_{u}$ and $\psi_{s}$ can be normalized to one. Therefore, we need to assign values to two parameters: the share parameter $\mu$ and the curvature parameter $\sigma$. We fix the parameter $\mu$ such that the average share of labor income paid to skilled labor in the model is equal to that in the data. The parameter $\sigma$ governs the elasticity of substitution between the two types of labor. We set this parameter equal to $\frac{1}{3}$, which yields an elasticity of substitution between unskilled labor and skilled labor of 1.5, which is consistent with estimates reported in the literature. (See Johnson (1997).)

The skill premium predicted by this version of our production function is presented in Figure 7. The large increase in the stock of skilled labor results in a monotonic decline in the skill premium of about 45 percent over the sample. This prediction from this version of the model obviously stands in sharp contrast to the actual skill premium. Clearly, if changes in observable variables are to account for observed changes in wage inequality in our model, it must be through the mechanism of capital-skill complementarity. Moreover, if the model is to be successful, this mechanism must not only offset the substantial negative trend in the skill premium produced by the relative increase in skilled labor, but also capture three other important features of the data: the modest increase in the premium during the 1960s, the decline over much of the 1970s, and the sharp increase after 1980. To provide an initial assessment of the implications of capital-skill complementarity for the skill premium, we conduct a second experiment in which the elasticity of substitution in our model between unskilled labor and equipment is higher than that between skilled labor and equipment. We continue to focus on the effects of observable variables on the skill premium, and therefore maintain the restriction that unmeasured labor quality of the two types is constant $\left(\psi_{u t}=\psi_{u}\right.$ and $\left.\psi_{s t}=\psi_{s}\right)$.

To conduct this second experiment, we need to choose values for the two key curvature 
parameters $\{\sigma, \rho\}$ as well as for the share parameters $\{\lambda, \mu\}$. One strategy for choosing values for the curvature parameters would be to use existing estimates of substitution elasticities. However, existing estimates of substitution elasticities between different types of labor and capital are based on measures of total capital, while in our model, the mechanism of capital-skill complementarity works through capital equipment. ${ }^{10}$ For this experiment, we use estimates of substitution elasticities from the literature to parameterize our model, and we treat these estimates from the literature as plausible values that make for a good starting point in our analysis. Our objective is to determine whether capital-skill complementarity appears to be quantitatively important for understanding variations in the skill premium based on substitution elasticities broadly in line with existing estimates.

In the second experiment, we use the production function nesting given in equation (6). We choose values for the curvature parameters that govern the substitution elasticities. To do this, we review the existing literature. A number of studies have estimated elasticities of substitution between capital and skilled labor and between capital and unskilled labor. These studies differ according to the choice of functional form, estimation technique, and data. Several studies are summarized by Hamermesh (1993). Many of the studies, including work by Rosen (1968), Griliches (1969), Berndt and Christensen (1974), Fallon and Layard (1975), Denny and Fuss (1977), and Brown and Christensen (1981), report evidence consistent with capital-skill complementarity in that the estimated elasticity of substitution between unskilled labor and capital is greater than that between skilled labor and capital. Many of the estimates of the elasticity of substitution between unskilled labor and capital in the literature are between 0.5 and 3 , while most of the estimates of the elasticity of substitution between skilled labor and capital are less than 1.2, and several are near 0. Based on these estimates, we choose an elasticity of substitution between unskilled labor and equipment of 1.5, which implies that $\sigma=0.33$. By symmetry, note that the elasticity of substitution between skilled labor and unskilled labor is also 1.5, which is consistent with the evidence summarized by Johnson (1997). We choose an elasticity of substitution between skilled labor and capital of 0.6, which implies that $\rho=-0.67$. Thus, we choose a parameterization for this experiment that is a fairly moderate departure from the Cobb-Douglas specification $(\sigma=\rho=0)$ of unit elasticities across all factors of production. We choose the share parameters $\{\lambda, \mu\}$ to match two statistics: the average (total) labor share of income over the period and the average ratio of skilled labor's share of income to unskilled labor's share of income. Finally, we require an estimate of $\alpha$, structures' share 
of income. Following Greenwood, Hercowitz, and Krusell (1996), we set $\alpha$ to 0.13.

The skill premium from this version of our model is shown in Figure 8, along with the actual skill premium. Clearly, the skill premium from the model with capital-skill complementarity stands in very sharp contrast to that from the model with identical elasticities of substitution shown in Figure 7. The introduction of capital-skill complementarity not only offsets the large decline in the premium generated by the large increase in the quantity of skilled workers, but it also captures the three main features of the skill premium over this 30-year period: the modest increase in the 1960s, the decline over much of the 1970s, and the sharp increase after 1980. The main conclusion we draw from these two experiments is that changes in observable variables, operating through the mechanism of capital-skill complementarity, can account for a significant fraction of the variation in the skill premium.

In the next section, we extend our analysis by asking whether our production function with capital-skill complementarity can account for historical variations in wage inequality while maintaining consistency with other important U.S. growth observations: the relative constancy of aggregate labor's share of income over time and a trendless rate of return on physical capital, with an average rate of return in the model near the average in the data. We include these observations in our analysis because they are frequently used to calibrate aggregate production functions in macroeconomics. (See, for example, Prescott (1986).) To conduct this extended analysis, we choose parameter values by estimating them using the first-order conditions of a profit-maximizing firm. This facilitates the analysis of the model along these other dimensions and allows us to explore possible connections between capital-skill complementarity and the importance of unmeasured trends in accounting for the skill premium reported in the literature.

\section{B An Extended Analysis}

The findings in the previous section indicate that capital-skill complementarity, with moderate differences in substitution elasticities between skilled labor and equipment and between unskilled labor and equipment, seems to be quantitatively important for understanding fluctuations in wage inequality over the last 30 years. However, the initial analysis focuses solely on the model's ability to account for wage inequality, and not other growth observations. In addition, the elasticities we chose for the previous exercises are based on measures of total capital, rather than capital equipment, 
which is the key measure of capital in our model. In this section, we develop an alternative method of choosing parameter values by estimating them from a representative firm's profit-maximization conditions.

The ideal way to obtain estimates of all the production function parameters would be to embed our production function in a fully specified, dynamic general equilibrium model in which the decisions for consuming, saving, choosing working hours, and becoming skilled versus unskilled are explicitly determined. Given a stochastic specification of the production function, these decision rules could be used in estimating the model parameters. Unfortunately, this type of analysis is much less tractable, largely because we would need to keep track of the entire distribution of the different types of labor. Since much of the difficulty in conducting the full general equilibrium analysis is due to the explicit modeling of household decisions, we abstract from the household side of the model and estimate the production function parameters directly.

We next describe the stochastic specification of the production function, and then describe the maximum-likelihood method used to estimate the parameters. Our general approach is to use the profit-maximization conditions of a firm hiring inputs in perfectly competitive factor markets. Since we have consistent time series data on skilled and unskilled labor input and their respective wages, we are able to use the first-order conditions for hiring skilled and unskilled labor in the estimation. Unfortunately, we do not have data on rental prices of capital equipment and structures, which

prevents us from using the first-order conditions for hiring these factors. Instead, we develop a proxy for these unobservable rental prices by equating the ex ante net return on equipment investment to the ex ante net return on structures investment. The equations used in the estimation are discussed in detail below.

\section{Stochastic Specification of the Production Function}

To estimate the model parameters, we must specify a stochastic version of our model. We assume that the efficiency factors of the two types of labor are random variables and that these variables are unobserved by the econometrician. ${ }^{11}$ We also assume that the relative price of capital equipment is a random variable, which allows us to specify our proxy condition for unobservability of rental prices of equipment and structures.

Following the analysis of the previous section, we will continue to focus our investigation on 
the extent to which changes in observable variables can account for fluctuations in the skill premium. Thus, our benchmark specification will continue to be the model with no variation in labor quality of the two types. To help interpret some interesting findings reported by Katz and Murphy (1992), we will also conduct some analyses in which we allow for trend differences in unmeasured labor quality of the two types. To facilitate a comparison with the model in Katz and Murphy (1992), we specify the stochastic process governing labor quality of the two types as the following simple trend stationary process (in logs):

$$
\varphi_{t} \equiv \log \left(\psi_{t}\right), \varphi_{t}=\varphi_{0}+\gamma t+\omega_{t}
$$

where $\varphi_{t}$ is a $(2 \times 1)$ vector of (logged) labor quality of the two types, $\varphi_{0}$ is a $(2 \times 1)$ vector of constants specifying the value of the efficiency factors at the beginning of the sample, $\gamma$ is a $(2 \times 1)$ vector of growth rates of the two types of labor quality, and $\omega_{t}$ is a vector shock process which we assume is multivariate normal and is i.i.d. with covariance matrix $\Omega: \omega_{t} \stackrel{i . i . d .}{\sim} N(0, \Omega)$. The i.i.d. assumption simplifies parameter estimation considerably. ${ }^{12}$

We use three structural equations to estimate the model parameters. The three equations are as follows:

$$
\begin{gathered}
\frac{w_{s t} h_{s t}+w_{u t} h_{u t}}{Y_{t}}=l s h_{t}\left(\psi_{t}, X_{t} ; \phi\right) \\
\frac{w_{s t} h_{s t}}{w_{u t} h_{u t}}=w b r_{t}\left(\psi_{t}, X_{t} ; \phi\right) \\
\left(1-\delta_{s}\right)+A_{t+1} G_{k_{s}}\left(\psi_{t+1}, X_{t+1} ; \phi\right)=E_{t}\left(\frac{q_{t}}{q_{t+1}}\right)\left(1-\delta_{e}\right)+q_{t} A_{t+1} G_{k_{e}}\left(\psi_{t+1}, X_{t+1} ; \phi\right) .
\end{gathered}
$$

Equations (10) and (11) are based on income shares implied by the firm's first-order conditions for hiring skilled and unskilled labor. These equations are similar to those used by Griliches (1969) in his initial study of capital-skill complementarity. Moreover, the approach of using income shares to help choose production function parameter values is also standard in the equilibrium business cycle and growth literature. (See, for example, Prescott (1986).) Equation (10) specifies that the total share of labor income in the model $\left(l s h_{t}\right)$, as defined using the marginal products from the production function, equals the aggregate labor share of income in the data. In this equation, the data for the left side of the equation are the ratio of labor income - defined as wages, salaries, and 
benefits - to the sum of labor and capital income - defined as depreciation, corporate profits, net interest, and rental income of persons. These definitions for labor and capital income are the same as those used in Cooley (1995). Equation (11) requires that the skilled labor share of income relative to the unskilled labor share of income in the data be equal to the corresponding production function object, which we denote $w b r_{t}$. This condition for the wage-bill ratio also follows from the firm's profit-maximizing decision in hiring skilled and unskilled labor.

Equation (12) develops a proxy for the unobservable rental rates of equipment and structures. We construct this proxy by equating the expected net rate of return on investment in structures with that on investment in equipment. This provides a simple way of ensuring that differences in rates of return are not implausibly large. The left side of this equation is the date $t+1$ rate of return on structures investment. This is equal to the sum of two components: (1) the marginal product of structures $A_{t+1} G_{k_{s}}\left(\psi_{t+1}, X_{t+1} ; \phi\right)$, where $G_{k_{s}}$ is the partial derivative of the production function with respect to structures, and (2) undepreciated capital structures $\left(1-\delta_{s}\right)$. The right side of the equation is the expected date $t+1$ rate of return on equipment investment. This also is equal to the sum of two components: (1) the marginal product of equipment investment $q_{t} A_{t+1} G_{k_{e}}\left(\psi_{t+1}, X_{t+1} ; \phi\right)$, where $G_{k_{e}}$ is the partial derivative of the production function with respect to equipment, and (2) undepreciated capital equipment multiplied by the expected rate of change in the relative price of capital $E_{t}\left(\frac{q_{t}}{q_{t+1}}\right)\left(1-\delta_{e}\right)$. Since the price of capital equipment tends to fall over time, the term $E_{t}\left(\frac{q_{t}}{q_{t+1}}\right)$ is interpreted as the expected capital loss on undepreciated equipment. The vector $\phi$ contains the parameters $\left\{\delta_{s}, \delta_{e}, \alpha, \mu, \lambda, \sigma, \rho, \eta_{\varepsilon}, \gamma, \Omega\right\}$ ( $\eta_{\varepsilon}$ will be defined below), and $X_{t}$ is the set of inputs $\left\{k_{s t}, k_{e t}, h_{s t}, h_{u t}\right\}$. In this equation, we assume that there is no risk premium, which allows us to abstract from the covariance between consumption and returns in the estimation procedure. We also assume that the tax treatments ${ }^{13}$ of these two types of investment are identical. ${ }^{14}$ The final simplifying assumption we make is to substitute the first term on the right side of the equation with $\left(1-\delta_{e}\right) q_{t} / q_{t+1}+\varepsilon_{t}$, where $\varepsilon_{t}$ is the i.i.d. forecast error, which is assumed to be normally distributed: $\varepsilon \sim N\left(0, \eta_{\varepsilon}\right) .{ }^{15}$ 


\section{Estimation Technique}

Because of the latent quality indicators of the two types of labor input, the model is a nonlinear state-space structure of the following form:

$$
\begin{aligned}
\text { measurement equations: } & Z_{t}=f\left(X_{t}, \psi_{t} ; \phi\right)+\varepsilon_{t} \\
\text { state equations: } & \varphi_{t}=\varphi_{0}+\gamma t+\omega_{t}
\end{aligned}
$$

where the function $f(\cdot)$ contains the three nonlinear observational equations - the rate of return equality condition and the two share equations - that are obtained as restrictions from our model. The income shares and the rate of return difference are contained in the $(3 \times 1)$ vector $Z_{t}, X_{t}$ is the set of inputs described above, $\psi_{t}$ is the $(2 \times 1)$ vector of unobservable efficiency factors in which the logs evolve according to the process specified in the state equation, and $\varepsilon_{t}$ and $\omega_{t}$ are, respectively, $(3 \times 1)$ and $(2 \times 1)$ vectors of i.i.d. normally distributed random disturbances with mean zero and covariance matrices defined in the previous section. ${ }^{16}$

This model is not straightforward to estimate because of the latent nature of $\psi_{t}$ and the nonlinearity of $f(\cdot)$. Indicating with superscript $T$ the vector of observations, we can write the joint probability distribution function (p.d.f.) of our model as $\psi\left(Z^{T}, \psi^{T} \mid X^{T}, \phi\right)$. Because $\psi^{T}$ is latent, we can only observe $\psi\left(Z^{T} \mid X^{T}, \phi\right)$. Therefore, in the structural estimation, we must collapse the first p.d.f. into the second to map the model into the data. The source of the difficulties in this operation originates exactly from the joint presence of the nonlinearity of the measurement equations and the stochastic latent variables. This joint difficulty prevents us from using standard Kalman filtering methods. Instead, we use simulation techniques to estimate the parameters of the model.

In a companion paper (Ohanian, Violante, Krusell, and Ríos-Rull (1996)), we analyze in detail the econometric issues associated with the specification and estimation of our model and compare the performance of different simulation-based estimation methods. This analysis focuses on the performance of different techniques in small samples with trending variables. The conclusion of this Monte Carlo study is that when the unobservable variables are specified as a trend stationary Gaussian multivariate process, a simulated pseudo maximum likelihood estimation (SPMLE) based on the first and the second moments is computationally efficient and produces parameter estimates 
in samples of size 30 with negligible bias. Based on these findings, we adopt this technique for estimating the parameters of the model. In Appendix 3, we describe briefly the general method of SPMLE and discuss its properties.

In this application, we use a two-step version of SPMLE as suggested by White (1994). This version of SPMLE is useful when some of the variables are potentially endogenous. In our analysis, we treat the date $t$ stocks of capital equipment and capital structures as predetermined, but we allow for the possibility that date $t$ values of skilled and unskilled labor input may respond to date $t$ realizations of the shocks to technology or to labor quality. The two-step procedure we use takes into account this potential endogeneity along the lines of other two-step estimators, such as twostage least squares. In the first step of the two-step SPMLE, skilled and unskilled labor input are projected onto exogenous variables. In the second step, the fitted values of these two series are used in SPMLE. Details of the estimation are described in Appendix 3.

The parameter vector $\phi$ has a dimension of 15 . We reduce the number of parameters that we estimate by calibrating some of the parameters and imposing some restrictions. One restriction is that the shocks to the log of skilled and unskilled labor efficiency are uncorrelated and have the same standard deviation. This implies that we can rewrite the covariance matrix $\Omega=\eta_{\omega}^{2} I_{2}$, where $I_{2}$ is the $(2 \times 2)$ identity matrix and $\eta_{\omega}^{2}$ is the common innovation variance. Other restrictions are required to set the scale, or the level, of our model. In the measurement equations, a number of parameters can act as scaling factors: $\varphi_{s 0}, \varphi_{u 0}, \lambda$, and $\mu$. It turns out that one of these parameters must be fixed. We choose to fix a priori the initial level of skilled labor efficiency $\varphi_{s 0}$. Note that this restriction is simply a normalization. We also are able to calibrate some of the parameters. We follow Greenwood, Hercowitz, and Krusell (1996) in choosing values for the depreciation rates of structures and equipment: $\delta_{s}$ and $\delta_{e}$. In addition, we estimate a time series (ARIMA) model for the relative price of equipment, $q_{t}$, and use the estimated innovation variance as the variance of the one-step forecast error for the relative price. The values for these calibrated parameters are presented in Table $1 .^{17}$

Table 1: Calibrated Parameters

\begin{tabular}{ccc}
\hline \hline$\delta_{s}$ & $\delta_{e}$ & $\eta_{\varepsilon}^{2}$ \\
0.05 & 0.125 & 0.02 \\
\hline \hline
\end{tabular}


The remaining parameters to be estimated are the key curvature parameter $\sigma$, which indexes the elasticity of substitution between unskilled labor and equipment $\left(\frac{1}{1-\sigma}\right)$; the other key curvature parameter $\rho$, which indexes the elasticity of substitution between skilled labor and equipment $\left(\frac{1}{1-\rho}\right)$; $\gamma_{u}$ and $\gamma_{s}$, the growth rates of unskilled and skilled labor efficiency; $\alpha$, structures' share of income; $\lambda$ and $\mu$, the weights in the CES nestings of the production function; $\psi_{u 0}$, the initial value for unskilled labor efficiency; and $\eta_{\omega}^{2}$, the variance of both labor efficiency factors.

\section{E Findings From the Estimated Model}

We first estimate the benchmark model, in which skilled labor requires at least four years of college and in which there are no trend changes in unmeasured labor quality. We estimate the model from 1963 to 1992 using the time series on labor input, wages, capital, and the relative price of capital. Table 2 shows the two-step SPML estimates and the asymptotic standard errors for the parameters of interest. The estimation is based on 500 simulations $(S=500)$, and standard errors are computed as described in Appendix 3.

\section{Table 2: Two-Step SPML Parameter Estimates-Benchmark Model}

\begin{tabular}{cccc}
\hline \hline$\sigma$ & $\rho$ & $\alpha$ & $\eta_{\omega}^{2}$ \\
0.401 & -0.495 & 0.117 & 0.043 \\
$(0.049)$ & $(0.169)$ & $(0.003)$ & $(0.003)$ \\
\hline \hline
\end{tabular}

Table 3: Elasticities of Substitution-Benchmark Model

\begin{tabular}{cc}
\hline \hline Unskilled Labor-Equipment $\left(\frac{1}{1-\sigma}\right)$ & 1.67 \\
Skilled Labor-Equipment $\left(\frac{1}{1-\rho}\right)$ & 0.67 \\
\hline \hline
\end{tabular}

These estimates are consistent with the basic theory of capital-skill complementarity and, in fact, are quite similar to the parameter values used in our second experiment in Section A. In particular, we chose $\sigma=0.33$ in our second experiment (a substitution elasticity between unskilled labor and equipment of 1.50), compared with the SPML estimate of $\sigma=0.40$ (a substitution elasticity between unskilled labor and equipment of 1.67). ${ }^{18}$ Similarly, we chose $\rho=-0.67$ in our second experiment (a substitution elasticity between skilled labor and equipment of 0.6), compared 
with the SPML estimate of $\rho=-0.50$ (a substitution elasticity of 0.67 ). It is also interesting to note that our estimate of the capital structures' share of income $(\alpha)$, which is about 12 percent, is very close to the 13 percent share calibrated by Greenwood, Hercowitz, and Krusell (1996). Figure 9 shows the behavior of our model relative to the data we used in the estimation. These data include (1) ex post rates of return on equipment and structures computed from our model (upper left panel), (2) aggregate labor's share of income in the model and in the data (lower left panel), and (3) the share of labor income paid to skilled labor in the model and in the data, that is the wage bill ratio (upper right panel). Recall that the production function parameters were chosen to minimize the distance between these objects and the data. ${ }^{19}$ The model statistics shown in this figure are produced with the i.i.d. shocks to both types of labor quality set to zero for every date. Consequently, fluctuations in model-generated data are entirely due to changes in observable inputs.

We find that the behavior of the estimated model is broadly consistent with the actual data. The model is able to capture the behavior of the relative income shares of skilled and unskilled labor (the wage bill ratio) very closely, as it reproduces the sharp, steady increase over this 30year period. The model is also consistent with the relative constancy of aggregate labor's share of income. The actual share data fluctuate modestly over the sample, ranging between 0.69 and 0.73. This limited variability of income shares in the data has led some economists to conclude that the aggregate production function is well approximated by a Cobb-Douglas function, since this technology restricts factor shares to be constant. (See, for example, Prescott (1986).) In comparison with the actual data, aggregate labor's income share in our model is smoother, fluctuating between 0.70 and 0.71. This finding is very interesting, since the nested CES production function we use, unlike the Cobb-Douglas technology, places no restrictions on the behavior of income shares over time and, in fact, can produce large fluctuations in income shares. The ex post rate of return on structures computed from our model averages about 4 percent and varies modestly between 3 percent and 5 percent. The ex post rate of return on equipment is more volatile than on structures, and this volatility is due to unexpected fluctuations in the relative price of equipment. For example, the ex post return on equipment in 1974 is about 17 percent, which reflects a very large unexpected increase in the price of equipment, while the near-zero rate of return on equipment in 1984 reflects a larger-than-expected decline in the relative price. ${ }^{20}$ The average rate of return on equipment in the model averages about 6 percent, compared with 4 percent on structures. This higher average is 
largely due to a few high returns in the late 1960s and early 1970s and to the very large outlier in 1974. It is important to note that the average levels of the rates of return on both types of capital are reasonable, despite the fact that neither our production function nor the estimation strategy places any restriction on the levels of these rates of return. Thus, an interesting finding is that our estimated production function produces sensible average rates of return on physical capital without explicit restrictions that impose this result. ${ }^{21}$

The skill premium predicted by the estimated model is presented in the lower right panel of Figure 9. We continue to find that the skill premium generated from the benchmark model is consistent with historical movements in the skill premium in the data. The model captures the three main changes in the skill premium that occurred over this 30-year period: The model correctly predicts an increase in the skill premium in the 1960s, it is consistent with the decline in the skill premium during the 1970s, and it also predicts the sharp increase in the skill premium that occurred after 1980. Thus, we find that our benchmark model, driven entirely by observable variables, not only can account for historical variation in the skill premium inequality over the sample, but also is consistent with the behavior of aggregate income shares of labor and capital over time, is consistent with the relative income shares earned by skilled and unskilled labor over time, and produces reasonable rates of return on physical capital.

We now draw a connection between our analysis, which focuses on the importance of capitalskill complementarity in accounting for changes in the skill premium, and other papers that have concluded that a key factor responsible for the increase in the skill premium is an unmeasured trend or another low-frequency component. Many economists (for example, Bound and Johnson (1992)) have defined this trend component as a skill-biased technological change that has shifted the demand for skilled labor. The quantitative importance of a trend component is reported in important work by Katz and Murphy (1992). They find that a simple supply-demand model specifying the log of the skill premium as a function of a linear time trend, which represents a relative demand shifter for skilled labor, and the log of the ratio of unskilled to skilled labor input can account for much of the variation in the skill premium over time. They estimate their equation using OLS and report the following coefficient estimates: 


$$
\log \pi_{t}=0.709 \log \left(\frac{h_{u t}}{h_{s t}}\right)+0.033 t
$$

Given the log-linear specification of this equation, the coefficient on the time trend means that the skill premium grows 3.3 percent each year, ceteris paribus. Consequently, the total contribution of the time trend over this 30-year period is to have increased the skill premium about 165 percent. While it has become common to call the trend effect skill-biased technological change, the explicit economic mechanism responsible for this large trend in the skill premium remains unspecified in the literature. We use our framework to provide one interpretation of the trend term in the KatzMurphy model, measure the magnitude of the trend effect in terms of objects in our model, and discuss the extent to which the trend term may be serving as a proxy for omitted capital-skill complementarity effects.

The Katz-Murphy model for the log of the skill premium can be derived from our model with equal elasticities of substitution between skilled labor and capital and between unskilled labor and capital (no capital-skill complementarity) and trend differences in the growth of labor quality. To illustrate this, consider the following version of our production function:

$$
y_{t}=A_{t} k_{t}^{\alpha}\left(\mu s_{t}^{\sigma}+(1-\mu) u_{t}^{\sigma}\right)^{\frac{1-\alpha}{\sigma}}
$$

where $k_{t}$ is the sum of capital structures and capital equipment.

When we omit the constant term, the log of the skill premium for this production function is simply

$$
\log \pi_{t}=(1-\sigma) \log \left(\frac{h_{u t}}{h_{s t}}\right)+\sigma \log \left(\frac{\psi_{s t}}{\psi_{u t}}\right)
$$

Given our specification for the log of labor quality,

$$
\varphi_{t} \equiv \log \left(\psi_{t}\right), \varphi_{t}=\varphi_{0}+\gamma t+\omega_{t}, \quad \gamma=\left[\begin{array}{c}
\gamma_{s} \\
\gamma_{u}
\end{array}\right]
$$

When we omit the constant and the disturbance term, the log of the skill premium in this version of our model is 


$$
\log \pi_{t}=(1-\sigma)\left(\frac{h_{u t}}{h_{s t}}\right)+\sigma\left(\gamma_{s}-\gamma_{u}\right) t
$$

Comparing the log of the skill premium from our model with no capital-skill complementarity to the Katz and Murphy (1992) regression indicates that the coefficient on the time trend in the Katz-Murphy model can be interpreted as the product of $\sigma$, the curvature parameter governing the elasticity of substitution between skilled and unskilled labor and the difference in the trend growth rates of skilled and unskilled labor quality, $\left(\gamma_{s}-\gamma_{u}\right)$. The implied estimates are shown in Table 4 . Based on the Katz-Murphy OLS estimates, the implied annual growth rate of skilled labor quality is more than 11 percentage points higher than that of unskilled labor quality. This implies that skilled labor quality has increased by a factor of about 30 relative to unskilled labor quality over this 30-year period. Thus, this analysis suggests that a large difference in the growth of relative labor quality over time is required to account for the skill premium in our model without capital-skill complementarity.

\section{Table 4: Implied Parameter Values From the Katz-Murphy Regression}

\begin{tabular}{ccc}
\hline \hline & $\sigma$ & $\gamma_{s}-\gamma_{u}$ \\
Estimate & 0.291 & 0.114 \\
\hline \hline
\end{tabular}

The data constructed by Katz and Murphy (1992) for skilled and unskilled labor differs somewhat from ours, since their analysis focuses on the difference between college and high school graduates. Therefore, we also estimate the parameters of this version of our model. To keep the comparison as close as possible, we follow Katz and Murphy (1992) and report coefficient estimates using OLS. ${ }^{22}$ We use only the equation involving the wage-bill ratio, since the Cobb-Douglas form generates a constant labor share of income $(\alpha)$ that we set to the sample average (0.705). Since only the difference in trends is identified in the Katz-Murphy model, we normalize trend growth in unskilled labor quality to zero, and we estimate only the trend coefficient on skilled labor quality. ${ }^{23}$ OLS yields the following coefficient estimates: ${ }^{24}$

\section{Table 5: Two-Step SPML Parameter Estimates-Model With Equal Elasticities}

\begin{tabular}{lll}
\hline \hline & $\sigma$ & $\gamma_{s}-\gamma_{u}$ \\
Estimate & 0.210 & 0.094 \\
\hline \hline
\end{tabular}


Our estimates of the parameters are quite similar to the implied estimates from the Katz and Murphy (1992) regression coefficients and, in particular, confirm that a substantial difference in the growth rates of skilled and unskilled labor quality is required to fit the data in the absence of capital-skill complementarity. The behavior of this version of our model is shown in Figure 10. A comparison of the results from our benchmark model (capital-skill complementarity and no trend changes in labor quality) with this version of our model (no capital-skill complementarity and large trend differences in relative labor quality growth) suggests that both versions can account for most of the variation in the skill premium. The Katz-Murphy analysis showed how a trend, or other low frequency component is important in accounting for the increase in the skill premium. Their analysis has also led researchers to (1) try to understand the explicit economic mechanism behind this unobserved trend, and (2) measure the changes in the data that are relevant for this mechanism.

We therefore argue that our version of the model without capital-skill complementarity is not very useful along these two dimensions. One key shortcoming of this version is that the fundamental economic factors driving the difference in trend growth of labor quality are unspecified. Consequently, our level of understanding changes in the skill premium is limited. The other shortcoming is that not only does the difference between the growth rates of labor quality seem implausibly large, but these objects are inherently difficult to measure. Our benchmark model, however, makes considerable progess along these dimensions. It provides an explicit and simple economic mechanism for understanding variation in the skill premium on the basis of observable variables, and it identifies the key factors that are important for this mechanism. Based on the similarity of the results between our benchmark model and the Katz-Murphy model, one conclusion that seems reasonable is that unmeasured trend effects may simply be serving as a proxy for omitted capital-skill complementarity.

We also estimated a third version of our model that allowed for both capital-skill complementarity and a difference in the growth rate of labor quality of the two types. We found that the estimates from this version did not change our conclusions regarding the importance of capital-skill complementarity: all of the elasticities of substitution in this model were quite similar to those in the benchmark model. The most striking difference between the benchmark model and this third version was that the fit of the skill premium (and the share of skilled labor income to unskilled labor income) was much better in the benchmark model - the mean square error of the skill premium 
was about twice as high in the third version. What accounts for the relatively poor performance of the third version of the model? Estimating the parameters of this version yields a modest difference in the growth rate of labor quality of the two types (3 percent higher for skilled labor), versus no trend growth in the benchmark model. This 3 percent difference is chosen only because it reduces the deviations in the ex ante rate of return equality restriction; the average equipment rate of return is only about 0.4 percentage point higher than that of structures in this third version. To assess this change in this version relative to the deterioration of the model's ability to account for the skill premium, it is important to note that the ex ante rate of return equality restriction was introduced as a very simple way of imposing sensible behavior on the difference between the rates of return on equipment and structures. However, this restriction abstracts from several factors which may prevent it from being satisfied exactly, including risk aversion on the part of investors and differences in tax treatment across assets. If investors are risk averse, higher net returns on equipment may be due to the substantially higher variability of these returns. In addition, we make the standard assumption that the physical depreciation rates of equipment and structures, which are key components in calculating net rates of return, are constant. Thus, we abstract from time variation in depreciation rates that can result from variations in factor intensity use or from changes in the composition of the capital stock over time. As a result, our rate of return equality restriction may contain measurement error. For these reasons, it seems sensible to discount the effect of the 3 percent time trend, since it only reduces the error on the rate of return equality restriction and actually worsens the ability of the model to account for the skill premium.

On the basis of these findings, we conclude that our benchmark model, driven by capital-skill complementarity and with no changes in unmeasured variables, accounts for most of the historical variation in the skill premium and provides a reasonable mechanism for interpreting the finding of skill-biased technological change presented in other studies. ${ }^{25}$ To gain further insight into how our theory helps us understand the behavior of the skill premium over this period, we present the results from two additional exercises. In our first exercise, we present a decomposition of the growth of the skill premium in our benchmark model into the three components defined in Section 3: the capitalskill complementarity effect, the relative supply effect, and the relative efficiency effect. Based on this decomposition, we reconstruct how these three components have affected the skill premium over the sample period. Recall that since there is no trend growth in labor quality in the benchmark model, 
all fluctuations in the skill premium are due to changes in either the capital-skill complementarity effect or the relative supply effect. The decomposition is presented in Figure 11: the sum of the three components gives the logarithm of the model skill premium plotted in the lower right panel. The levels in the figure are measured in logs, just as in the decomposition. The lower right panel, which is the skill premium, is the sum of the data presented in the other three panels. This figure clearly shows that both the relative supply of labor and capital-skill complementarity have had very large and very different effects on the skill premium over this period. The relative supply effect is presented in the upper right panel. Given the significant increase in the relative quantity of skilled labor input over this period, the relative supply effect is consistently negative and can be seen to have reduced the skill premium by more than 40 percent over the sample. In particular, we find that the relative supply effect was an important factor in the decline of the skill premium during the 1970s. This finding is consistent with Katz and Murphy (1992). The contribution of the capital-skill complementarity effect is presented in the upper left panel. This factor is clearly the driving force behind the increase in the skill premium over the sample period. The total effect of capital-skill complementarity is to have increased the skill premium by nearly 60 percent over the sample. We find that this factor was particularly important in the 1960s, increasing the skill premium about 2.5 percent per year on average, and also after 1980, increasing the skill premium by about 2.1 percent per year. Between 1969 and 1979, however, this factor had a smaller positive effect, increasing the skill premium only about 1.4 percent per year.

Our final exercise provides further information on the importance of the capital-skill complementarity effect in understanding wage inequality. We use our benchmark model to simulate the evolution of the skill premium under a counterfactual assumption on the growth rate of capital equipment. In this counterfactual exercise, the implied skill premium from our benchmark model is generated under the assumption that the post-1975 average growth rate of capital equipment was equal to its lower pre-1975 average growth rate. We find that if equipment had grown at its pre-1975 average rate in the post-1975 period, the skill premium would have risen just 2 percent relative to its value in 1963. This is substantially less than the 18 percent increase predicted by the model under the actual time path of the stock of equipment. 


\section{Summary and Conclusion}

Over the last 30 years, the growth rates of labor input quantities and prices have changed dramatically. The quantity of skilled labor input relative to unskilled labor input has increased considerably, and relative wages of skilled labor have also grown significantly since 1980 . The conclusion reached by most studies is that observable variables can account for only a small fraction of increased wage inequality and that implicit trend growth in skill-biased technological change is the key factor responsible for these changes. Despite this widespread conclusion, there is no standard theory for interpreting skill-biased technological change, nor are there direct measures of this object. This paper develops a neoclassical framework in which capital-skill complementarity is the driving force behind increased wage inequality. Capital-skill complementarity provides a simple, explicit mechanism for understanding skill-biased technological change: rapid growth in the stock of capital equipment, combined with the different ways equipment interacts with skilled and unskilled labor input in the production technology, has increased the marginal product of skilled labor while decreasing the marginal product of unskilled labor.

Our main finding is that capital-skill complementarity is an important missing factor in understanding historical variation in the skill premium. With moderate capital-skill complementarity, we find that changes in observed factor quantities can account for the variation in wage inequality over the last 30 years. Without capital-skill complementarity, we find that the skill premium would have declined about 45 percent over the period. Moreover, our benchmark model, with capital-skill complementarity but no changes in unobserved variables, not only accounts for changes in the skill premium, but is also consistent with other important long-run U.S. growth observations, including the behavior of aggregate and relative income shares over time, and is consistent with reasonable of rates of return on capital. These quantitative predictions, together with the simplicity of this model, suggest that it can be used to study other questions related to capital-skill complementarity. On the basis of our quantitative analysis, we conclude that the common empirical finding of trend growth of skill-biased technological change as an important determinant of wage inequality may simply be serving as a proxy for omitted capital-skill complementarity.

Our findings have important implications for growth and the formulation of economic policy. While the development of better and cheaper capital equipment benefits the economy as a whole, 
our results quantitatively show how this development can significantly drive down the relative wages of unskilled workers. As a result, growing wage inequality can be a consequence of economic growth that is driven by technological progress in the production of new capital equipment. As the gap between wages for skilled and unskilled workers has increased, a number of economic policies have been proposed to narrow the wage inequality. One popular policy proposal is to increase trade barriers and increase the price of imported goods in order to protect domestic unskilled labor from competition with low-wage foreign labor. However, our findings suggest that these types of policies will not be very effective, since unskilled labor is competing not only with foreign labor, but also with persistently cheaper and better capital equipment. Instead, our results suggest that the key to narrowing inequality may be through increased education and training for unskilled workers. By improving skills, workers can utilize new equipment and raise their own productivity, rather than be replaced by new machines. 


\section{Appendix 1. Labor Input Data}

The sources of our data are the CPS Annual Demographic Uniform March Files (CPS_UM) for the years 1964-88 and the CPS Annual Demographic March Files (CPS_M) for the years 198993. The former are just a standardized version of the latter; hence, they are easier to use for that sample period. Following Katz and Murphy (1992), we drop nonreporting individuals from the sample, since the Census Bureau changed its imputation methods for nonreporting individuals midway through our sample.

We have restricted our attention to all people between 16 and 70 years old, excluding the self-employed. The series for skilled and unskilled labor input and wages are constructed in two steps. In the first step, several hundred demographic groups are constructed, and some variables are recorded in each group. In the second step, these few hundred groups are sorted into two categories: skilled labor and unskilled labor. The key variables are aggregated across groups to obtain categoryspecific averages. In the second step, there is some weighting of the variables which goes beyond the CPS weighting scheme needed for adjusting the sampling probability.

In what follows, we describe how the groups were constructed, what criteria we used to sort the demographic groups into skilled and unskilled categories, and how the group variables were aggregated and weighted to construct the measures of skilled and unskilled labor input and wages used in the paper.

\section{Individual Variables}

For each person, we recorded demographic characteristics, such as age, race, sex, and years of education, as well as the CPS weights. We also recorded current employment status, weeks worked last year, hours worked last week, and labor income earned last year. ${ }^{26}$ In Table A.1, we report these variables, along with the label used in the paper, and their counterpart and position in the CPS files. The index $i$ is used for workers and the index $t$ for the current year.

\section{Construction of Demographic Groups}

All workers in the sample are grouped according to their demographic characteristics. The groups we consider are distinguished by the following: 
- Age. There are 11 five-year groups.

- Race. Race variables are grouped into white, black, and others.

- Sex.

- Education. The education status is grouped as follows:

1. $E_{i} \leq 11$ : No high school diploma.

2. $E_{i}=12$ : High school graduate.

3. $12<E_{i} \leq 15$ : Some college.

4. $E_{i}>15$ : College graduate and more.

Each worker is assigned to one group defined by age, race, sex, and education. We have 264 of these groups, each of which generates a partition of the population in the sample and which we denote by $g \in G$. For each one of these partitions, we need to construct an average measure of the labor input and the labor earnings. For the computation of the group labor input, we must take into account the labor input of those workers who reported zero hours worked last week. (This can occur although they worked last year for a positive number of weeks: the week before the survey they were either unemployed or, if they had a job, they were not at work.) We have made this correction by assuming that their weekly supply of hours is equal to that of the average worker with nonzero hours worked belonging to their same group. Hourly wage is just the ratio between last year's labor income and last year's measure of labor input (in hours). First, we obtain the following measures of individual labor input $l_{i t}$ and hourly wage $w_{i t}$ :

$$
\begin{array}{ll}
l_{i, t-1}=h_{i t} w k_{i, t-1} & \text { if worked last week, } \\
l_{i, t-1}=\bar{h}_{g t} w k_{i, t-1} & \text { if did not work last week, } \\
w_{i, t-1}=\frac{y_{i, t-1}}{l_{i, t-1}} &
\end{array}
$$

where $\bar{h}_{g t}=\frac{\sum_{i \in g} 1\left(l f s_{i t}=e\right) h_{i t} \mu_{i t}}{\sum_{i \in g} 1\left(l f s_{i t}=e\right) \mu_{i t}}$. Therefore, for the whole group $g$, we obtain 


$$
\begin{aligned}
l_{g, t-1} & =\frac{\sum_{i \in g} l_{i, t-1} \mu_{i t}}{\sum_{i \in g} \mu_{i t}} \\
w_{g, t-1} & =\frac{\sum_{i \in g} w_{i, t-1} \mu_{i t}}{\sum_{i \in g} \mu_{i t}} \\
\mu_{g, t-1} & =\sum_{i \in g} \mu_{i t} .
\end{aligned}
$$

\section{Aggregation of Groups Into Skilled and Unskilled Categories}

The next step is to aggregate the set $G$ of 264 groups indexed by $g$ into skilled, that is, $g \in G_{s t}$, and unskilled, that is, $g \in G_{u t}$, categories and compute measures of the total annual labor input for skilled workers $N_{s t}$ and of their hourly wage $W_{s t}$, as well as total annual labor input for the unskilled $N_{u t}$ and their hourly wage $W_{u t}$. Skilled workers are those with a minimum number of years of education. For the first criterion (EDU_COL), skilled workers have at least a college degree; unskilled workers are all the rest. This partition is time invariant; that is, the groups of $G$ that belong to the skilled category are always the same.

\section{Skilled and Unskilled Total Labor Input and Hourly Wage}

The key problem, at this stage, is how to aggregate group-specific measures into the broad classes of skilled and unskilled labor defined by the criteria above. In doing this, we assume that the groups within a class are perfect substitutes (they simply add), and for the aggregation we use as weights the group wages of 1980 in very much the same way that real gross domestic product is computed in the NIPA. Let $j=s, u$ indicate the skilled and the unskilled type, respectively. Then the total labor input (in hours) for the two categories is

$$
N_{j, t-1}=\sum_{g \in G_{j t}} l_{g, t-1} w_{g, 80} \mu_{g t}
$$

The average hourly labor income is, therefore, just

$$
W_{j, t-1}=\frac{\sum_{g \in G_{j t}} w_{g, t-1} l_{g, t-1} \mu_{g t}}{N_{j, t-1}} .
$$

Finally, note that we have CPS data for the period 1964-93, but since wages and labor input data in the survey always refer to one year earlier, our sample spans the period 1963-92. 


\section{Appendix 2. Capital Stock Data}

In the model, we have two types of capital: structures and equipment. Central to the model is the observation that the price of equipment has declined relative to the price of nondurable consumption goods and services and to the price of capital structures. Since, in the data, the behavior of the two latter prices is very similar, we have assumed a unique price for both consumption and structures. This price index (P_CONS) is obtained from the implicit price deflators for nondurable consumption and services. The implied average growth rate of consumption prices for the period is 5.3 percent. For the measurement of structures, we follow Greenwood, Hercowitz, and Krusell (1996).

The measurement of capital equipment is a more complex matter, as we are interested in the efficiency units of equipment that enter as an input of the production function in each period. To obtain efficiency units, we need to compute their relative prices. Because of the huge improvement in the quality of equipment goods that has occurred over the last 10-15 years, especially for information processing equipment, quality-adjusted price indices are needed for a meaningful and reliable measure of this relative price. Unfortunately, the NIPA series does not contain any adjustment for improved quality until 1992, when a quality-adjusted price series for computers and peripherals became available starting from 1982. Many economists regard this adjustment as still unsatisfactory, since the methodology followed - a matching models procedure - is likely to understate the dramatic

price decline which occurred in computers in the 1980s and is ongoing in the $1990 \mathrm{~s}^{27}$ Moreover, the categories other than computers and peripherals have no adjustment at all. We first present a breakdown of the producers' durable equipment (PDE) into categories, as it is in the NIPA, to introduce some labels we will be using hereafter:

- Office information processing (OIP).

- Office computing and accounting machinery (OCAM).

* Computers and peripherals (COMP).

* Other $(\mathrm{OFF})$.

- Other office and information processing (OTHOIP).

* Communications (COMM). 
* Instruments, photocopy, and related equipment (INST).

- General industrial equipment (INDEQ).

- Transportation (TRANSP).

- Others (OTHER).

Figure 12 shows the relative nominal shares of the four main categories, according to the NIPA. As expected, the share of OIP doubled in the observed period, and all the increase seems to happen especially between 1979 and 1985.

\section{Quality Adjustment for Prices of Equipment}

The price index we have used to aggregate all the quality-adjusted prices for the different categories of PDE and to obtain a unique corrected price index for capital equipment is a Törnqvist index (TORN). If we assume that there are $N$ goods, labeled $i=1, \ldots, N$, the change of the TORN price index from $t-1$ to $t$ is given by

$$
\Delta T O R N_{t}=\sum_{i=1}^{N} \log \left(\frac{p_{t}^{i}}{p_{t-1}^{i}}\right) \frac{\left(s_{t}^{i}+s_{t-1}^{i}\right)}{2}
$$

where $p_{t}^{i}$ is the price level of good $i$ in year $t$ and $s_{t}^{i}$ is the nominal expenditure share on good $i$ in year $t$. This index is an annual chain-weighted index; that is, the nominal value shares used to aggregate the prices of the categories are not fixed to a given base year, but they change every year. Chain-weighted indices such as Törnqvist or Divisia provide better approximations than fixedweight indices for rapidly changing prices and shares. In cases where there is a fast decrease in the price of some commodities, as there is in our case, a fixed-weight index would overstate the decline before, and understate it after, the base year, and, in general, the behavior of the index would depend heavily on the choice of the base year.

Gordon (1990) computes a quality-adjusted Törnqvist index for PDE for the period 1947-83; hence, for the sample period up to 1983, we rely on Gordon's (1990) data. For the sample period after 1983, we are not aware of any existing quality-adjusted series for the categories above that can be used, except for computers, for which a fairly large literature on quality-adjustment has developed recently. Hence, we need to construct the series ourselves. As a first step, we aggregate 
the 16 primary categories used by Gordon (1990) into the four main groups: OCAM, INDEQ, TRANSP, and OTHER. The price indices for the INDEQ, TRANSP, and OTHER categories did not change dramatically in the 1980s, unlike computers. It is likely, hence, that the relationship between the quality-adjusted and the official price indices has stayed approximately stable over time for these categories. Therefore, we forecast the quality-adjusted prices for 1983-92 using the series of the official NIPA price indices, which are available up to 1992.

We first estimate a vector autoregression (VAR) for the period 1963-83 on the qualityadjusted price indices for INDEQ, TRANSP, and OTHER in levels (in order to exploit their possible cointegration) using their past values, the lagged official NIPA price indices, and a lagged indicator of the cycle as exogenous regressors. ${ }^{28}$ Then we forecast recursively up to 1992 , exploiting the fact that the exogenous variables are observable also for that period. The results of the estimation are in Table A.2, and the series is shown in Figure 13. Until 1983, the values are from Gordon's (1990) series; starting from 1984, values are forecasted. P_CONS is also plotted for comparison.

The computation of an accurate quality-adjusted series for OIP is a key issue, since this is the group that recorded the largest change in price and relative share. We first split the OIP group into COMP and all the OIP categories other than computers and peripherals (OFF, COMM, and INST). For communication equipment and instruments, we use the same forecasting technique as before, but we fit two separate equations this time, as the data before 1984 do not show any strong comovements.

\section{Results of Estimation on P_COMM and P_INST}

\begin{tabular}{|c|c|c|||c|c|c|}
\hline \multicolumn{2}{|c||}{ Dependent Variable: P_COMM } & \multicolumn{3}{c|}{ Dependent Variable: P_INST } \\
\hline Variable & Coefficient & t-stat. & Variable & Coefficient & t-stat. \\
\hline Constant & -0.62 & -0.162 & $\mathrm{c}$ & 1.89 & 3.36 \\
\hline $\mathrm{AR}(1)$ & 0.90 & 7.80 & $\mathrm{AR}(1)$ & 0.68 & 5.63 \\
\hline $\mathrm{MA}(4)$ & 0.91 & 2.11 & $\mathrm{MA}(2)$ & -0.64 & -3.27 \\
\hline OP_COMM(-2) & -0.32 & -2.84 & OP_INST(-1) & 0.06 & 0.61 \\
\hline DLAGG(-2) & 0.01 & 2.64 & DLAGG(-5) & -0.02 & 4.03 \\
\hline $\bar{R}^{2}=0.87$ & & $\bar{R}^{2}=0.97$ & & \\
\hline
\end{tabular}

Remark: The prefix OP_ indicates the official NIPA series. 
The table above shows the results of the estimation over the 1963-83 sample period, which make up the model from which we forecast the quality-adjusted price up to 1992. In Figure 14, the growth rates in the COMM and INST categories are plotted for the relevant period. The obtained values have sensible magnitudes, and the fact that they comove significantly after 1983 confirms the reliability of the forecast. For the OFF category, we take the official NIPA price index, as we conjecture that the quality-adjustment would not be very relevant.

For computers and peripherals, a large literature on quality-adjusted price indices is available. We made an effort to reconstruct a meaningful index from some of these pieces of work. The COMP category is composed of personal computers (PCs), other computers (mainframes, supercomputers, workstations, and midrange computers), and peripherals. Computers and peripherals held by consumers are not relevant for our measure of capital input; therefore, we consider only the durables used in the business sector. From the Statistical Abstracts of the United States, we get that the share of PCs in the business sector increased from 37 percent to 57 percent of the total expenditure in PCs in the decade considered. ${ }^{29}$ Assuming that all the other types of computers are held by the business sector and that peripherals are shared between the home and the business sectors in the same proportion as computers, we get that the share of workstations, mainframes, and other computers of the total expenditure on COMP declined from 46 percent to 35 percent, while the share of PCs increased from 9 percent to 21 percent between 1983 and 1992. The share of peripherals was constant at around 44 percent of total COMP.

In terms of adjusted price indices associated to these shares, the only existing adjusted price index for peripherals is computed by Cole et al. (1986) for the period 1972-84. It shows an average decline of 10 percent, which is lower (in absolute value) by a factor of 1.3 than the corresponding magnitude for the total adjusted price series for OCAM in the same period, taken from Gordon (1990). Using the shares of the categories, we compute that the ratio of the decline in the price of peripherals and to that of PCs and mainframes is 0.65. We assume that this ratio also holds for the period 1984-92; so, given the adjusted price indices for different types of computers, we can recover that of peripherals, too. Brown and Greenstein (1995) compute an adjusted series for prices of mainframes, and they find that in the period 1985-91, their price declined by 30 percent, on average, every year. We assume that their numbers also hold for all the other types of computers, except PCs. Berndt, Griliches, and Rappaport (1995) compute a hedonic-adjusted price index for 
PCs from 1989 to 1992 and conclude that the price declined by more than 29 percent a year. Moreover, they report a result from a previous study that covered 1983-88, for which the average decline was 22 percent. $^{30}$ For the missing years, we assume that the change in price is an average of the change in the previous and the next year, when the point of the sample is interior, as in 1989 for PCs. Otherwise, we assume that the price change equals that for the closest year for which an observation was available, as for 1983, 1984, and 1992 for mainframes.

In Figure 15, the resulting price index for computers based on the literature is compared to the NIPA index - an implicit price deflator (IPD) with a base year of 1987 — which is adjusted for quality, too, as mentioned above. Our results confirm the general impression that the NIPA index still underestimates the true decline in price for COMP. It is also interesting to note that, compared with the chain-weighted Törnqvist index, the NIPA index overestimates the decline in the price index before the base year and underestimates it afterward, as expected, since the so-called substitution bias is very strong for this group of goods.

Using the above data on price indices and shares, subject to the assumptions made, we can construct the series for quality-adjusted price indices for the aggregate of OIP with a Törnqvist procedure.

\section{Time Series of Adjusted Price Indices and Efficiency Units of Capital Equipment}

At this point, we can use the procedures described in the previous sections of the appendix to obtain series for relative prices and efficiency units of capital equipment for the whole period 1963-92. First, we aggregate the price indices for the four main categories with the Törnqvist procedure. The relative price index is constructed by dividing the aggregate TORN price series through P_CONS. In Figure 2, the growth rates of the relative price index series are compared with the NIPA series of relative prices obtained by dividing the official IPD of PDE (base year 1987) by P_CONS.

Investment in capital equipment in efficiency units is constructed by deflating the nominal series of investment in equipment from the NIPA through our quality-adjusted price index for equipment. The series for capital equipment is obtained starting from a value of capital which matches the investment-capital ratio in Gordon (1990) (Table 12.6) for 1963 and recursively constructing capital the next period with investments and the depreciation rate of 0.125 calibrated as described in Section 5 of the paper. Figure 16 reports our series of growth rates of capital equipment and the 
series implied by the official NIPA data. The following table summarizes the average growth rates of the relative price and the capital stock in efficiency units for our computation and for the NIPA data before and after 1980, the key year in the time pattern of the skill premium.

\begin{tabular}{||l|c|c||}
\hline \hline Growth Rate & $1963-79$ & $1980-92$ \\
\hline Rel. Price NIPA & -0.003 & -0.026 \\
Rel. Price TORN & -0.036 & -0.060 \\
\hline Capital Equip. NIPA & 0.046 & 0.034 \\
Capital Equip. TORN & 0.068 & 0.074 \\
\hline \hline
\end{tabular}

We report in Table A.3 the Citibase denomination of all the series taken from the NIPA for the construction of our series on capital equipment and its relative price.

Table A.1: Variables Used For Data On Labor Input and Wages

\begin{tabular}{||l|l|l|l||}
\hline \hline Variable & Label & CPS_UM (Position) & CPS_M (Position) \\
\hline Age & $a_{i t}$ & Age in Years (93) & Age in Years (15) \\
Race & $r_{i}$ & Race (179) & Race (25) \\
Years of Education & $s_{i}$ & Sex (183) & Sex (20) \\
Employment Status & $l f s_{i t}$ & Highest Grade (124 and 99) & Highest Grade (22 and 24) \\
Weeks Worked & $w k_{i, t-1}$ & Weeks Worked Last Year (205) & Weeks Worked Last Year (171) \\
Weekly Hours Worked & $h_{i, t}$ & Hours Worked Last Week (126) & Hours Worked Last Week (76) \\
Labor Income & $y_{i, t-1}$ & Person's Wage and Salary (187) & Total Wage and Salary Earnings (243) \\
Weight & $\mu_{i t}$ & Person's Suppl. Weight (281) & March Suppl. Person Weights (66) \\
\hline \hline
\end{tabular}


Table A.2: VAR Estimation Results

\begin{tabular}{||c|c|c|c||}
\hline \hline & P_INDEQ & P_TRANSP & P_OTHER \\
\hline $\mathrm{c}$ & 1.52 & 1.55 & 0.44 \\
& $(1.66)$ & $(2.50)$ & $(0.43)$ \\
\hline P_INDEQ(-1) & 0.39 & -0.38 & 0.94 \\
& $(0.72)$ & $(-1.17)$ & $(1.8)$ \\
\hline P_TRANSP(-1) & -0.64 & 0.28 & -0.26 \\
& $(-2.38)$ & $(1.54)$ & $(-0.88)$ \\
\hline P_OTHER(-1) & -0.40 & -0.01 & -0.52 \\
& $(-0.94)$ & $(-0.04)$ & $(-1.14)$ \\
\hline OP_INDEQ(-1) & 3.02 & 1.88 & 7.10 \\
& $(2.30)$ & $(1.57)$ & $(2.54)$ \\
\hline OP_TRANSP(-1) & -0.05 & 0.26 & 1.00 \\
& $(-0.04)$ & $(0.31)$ & $(0.76)$ \\
\hline OP_OTHER(-1) & -0.48 & -0.75 & -6.51 \\
& $(-0.24)$ & $(-0.56)$ & $(-2.98)$ \\
DLAGG & -0.01 & -0.01 & -0.00 \\
& $(-1.27)$ & $(-2.65)$ & $(-0.11)$ \\
\hline \hline$R^{2}$ & 0.990 & 0.976 & 0.989 \\
\hline \hline
\end{tabular}

Table A.3: Variables Used For Data On Equipment

\begin{tabular}{||l|l||}
\hline \hline Variable & $\begin{array}{l}\text { Citibase } \\
\text { Label }\end{array}$ \\
\hline PDE & GIPD \\
PDE (in 1987 prices) & GIPDQ \\
Computers and peripherals & GIPCP \\
OCAM & GIPOS \\
Other OCAM & GIPOC \\
Communications & GIPCE \\
Instruments & GIPIS \\
Photocopy and related equipment & GIPPE \\
Industrial equipment & GFINE \\
Transportations & GFINT \\
Other PDE & GFNPO \\
\hline IPD for nondurable consumption & GDCN \\
IPD for services & GDCS \\
\hline \hline
\end{tabular}




\section{Appendix 3. Econometric Technique}

For the estimation of our model we use the simulated pseudo maximum likelihood estimation (SPMLE) algorithm. The theory of pseudo maximum likelihood estimation (PMLE) was developed by White (1982) and Gouriéroux, Monfort, and Trognon (1984). The PMLE is based on the idea that one can approximate the unknown or intractable likelihood function with a simpler objective function constructed from some empirical moments of the dependent variables. When these moments cannot be obtained analytically, under some fairly general conditions they can be simulated: this latter extension of the original PMLE method is called SPMLE and is due to Laroque and Salanié (1989), Laroque and Salanié (1993), and Laroque and Salanié (1994). The two-step version we use to correct for potential endogeneity is due to White (1994). The notation that follows is the same as that used in the text.

\section{Description of the Estimation Method}

The simplest way of conducting the analysis would be to assume that the left side variables in the equations (the factor shares and expected rates of return) are endogenous and that the factor inputs are exogenous. This simple approach implicitly assumes that labor supply is predetermined at any point in time and thus abstracts from the potential effect of the i.i.d. labor quality shocks on hours worked. To allow for the possible dependence of hours worked on shocks, we use the two-step SPMLE procedure developed by White (1994), which is similar in spirit to two-stage least squares. We therefore treat skilled and unskilled labor input as endogenous, and we project these variables onto a constant, current, and lagged stock of capital equipment; current stock of capital structures; the lagged relative price of capital equipment; a time trend; and the lagged value of the Commerce Department's composite index of business cycle indicators. The fitted (instrumented) values of skilled and unskilled labor input from this first-stage regression are then used in a secondstage analysis described below. We define the vector $\widetilde{X}_{t}$ as consisting of the stocks of equipment and structures and of the instrumented values of skilled and unskilled labor input. While we allow for dependence of the labor input on shocks, we treat the capital stocks as predetermined variables. We argue that this is a reasonable approach, since the stocks of capital evolve very slowly over time, and thus will tend not to respond much to these i.i.d. shocks.

In the second stage of the analysis, we use the instruments and instrumented values of the 
labor input series with the SPMLE. This proceeds as follows: given the distributional assumptions on the error terms, for each year $t$ observation we generate $S$ realizations of the dependent variables each indexed by $i$, by following two steps:

$$
\text { Step 1: } \varphi_{t}^{i}=\varphi_{0}+\gamma t+\omega_{t}^{i}
$$

$$
\text { Step 2: } \quad Z_{t}^{i}=f\left(\tilde{X}_{t}, \varphi_{t}^{i}, \varepsilon_{t}^{i} ; \phi\right)
$$

In Step 1, a realization of $\omega_{t}$ is drawn from its distribution and used to construct a year $t$ value for $\varphi_{t}$. In Step 2, this realization of $\varphi_{t}$, together with a draw of $\varepsilon_{t}$ allows us to generate a realization of $Z_{t}$.

By simulating the model through (A1), we can obtain the first and second moments of $Z_{t}$ :

$$
\begin{aligned}
& m_{S}\left(X_{t} ; \phi\right)=\frac{1}{S} \sum_{i=1}^{S} f\left(\tilde{X}_{t}, \varphi_{t}^{i}, \varepsilon_{t}^{i} ; \phi\right) \\
& V_{S}\left(X_{t} ; \phi\right)=\frac{1}{S-1} \sum_{i=1}^{S}\left(Z_{t}-f\left(\tilde{X}_{t}^{i}, \varphi_{t}^{i}, \varepsilon_{t}^{i} ; \phi\right)\right)\left(Z_{t}-f\left(\tilde{X}_{t}^{i}, \varphi_{t}^{i}, \varepsilon_{t}^{i} ; \phi\right)\right)^{\prime}
\end{aligned}
$$

On the basis of these moments constructed for each $t=1, \ldots, T$ we can write the objective function as

$$
\begin{aligned}
\ell_{S}\left(Z^{T} ; \tilde{X}^{T}, \phi\right)= & \frac{1}{2 T} \sum_{t=1}^{T}\left\{\left[Z_{t}-m_{S}\left(\tilde{X}_{t} ; \phi\right)\right]^{\prime}\left(V_{S}\left(\tilde{X}_{t} ; \phi\right)\right)^{-1}\left[Z_{t}-m_{S}\left(\tilde{X}_{t} ; \phi\right)\right]\right. \\
& \left.+\log \operatorname{det}\left(V_{S}\left(\tilde{X}_{t} ; \phi\right)\right)\right\}
\end{aligned}
$$

The SPML estimator $\widehat{\phi}_{S T}$ is defined simply as the maximizer of (A2). Note that throughout the maximization procedure of the objective function, the same set of $(T \times S)$ random numbers for each component of the three-dimensional vector of shocks must be used to prevent the likelihood from becoming a random function.

\section{Properties of the SPMLE Method}

The SPMLE method has intrinsically two sources of bias. One comes from the approximation of the objective function: instead of the intractable original likelihood, we use a simpler objective function. The other originates from the fact that the true moments are replaced by the simulated 
ones, inducing some simulation uncertainty. In our application, there is a third potential source of bias due to the small sample.

Laroque and Salanié (1989) proved that the original consistency result of Gouriéroux, Monfort, and Trognon (1984) extends to an environment where the moments of the endogenous variable need to be simulated. Under stationarity of the series, if the pseudo distribution belongs to the quadratic exponential family, as in our specification, then there is no approximation bias and the SPMLE is consistent and asymptotically normal so, as $S \rightarrow \infty, T \rightarrow \infty$, and $\frac{\sqrt{T}}{S} \rightarrow o$,

$$
\sqrt{T}\left(\widehat{\phi}_{S T}-\phi_{0}\right) \rightarrow N\left(0, J_{0}^{-1} I_{0} J_{0}^{-1}\right)
$$

where $I_{0}=E_{0}\left\{\frac{\partial \ell\left(Z_{t} ; X_{t}, \phi\right)}{\partial \phi} \frac{\partial \ell\left(Z_{t} ; X_{t}, \phi\right)}{\partial \phi^{\prime}}\right\}$ and $J_{0}=E_{0}\left\{-\frac{\partial^{2} \ell\left(Z_{t} ; X_{t}, \phi\right)}{\partial \phi \partial \phi^{\prime}}\right\}$. We use $E_{0}$ to denote the expectation with respect to $Z_{t}$ and $X_{t}$ taken under $\phi_{0}$, the true parameter value. As far as the simulation bias is concerned, Laroque and Salanié (1994) prove that this bias has the order of $\frac{1}{S}$ and, according to their Monte Carlo experiments, for $S=20$ the bias is already extremely small.

These theoretical results on the SPMLE are asymptotic and hold for stationary environments. In our analysis, however, the regressors and the latent variables have trends and the sample size is small. To investigate the performance of this estimator in small samples and with trending processes, we conducted in Ohanian et al. (1996) a Monte Carlo analysis on the properties of this estimator under these conditions. In particular, we took a version of our production function with capital-skill complementarity, simulated generated data from the model under assumed parameter values, and then estimated the parameters using the SPMLE. We analyzed the case in which the data were both trend stationary and difference stationary. We found that for trend stationary processes, there is very little mean and median bias in the estimated parameters of the model even for $S=10$. This finding is consistent with the results of Laroque and Salanié (1994), who considered a different model. For $S=50$, we found that the mean bias is essentially zero in our model for the key curvature parameters $\sigma$ and $\rho$.

One could, in principle, improve on the SPMLE by running indirect inference with the SPMLE as a first-step estimator. This procedure, given the presumed consistency of the firststep estimation method, would provide a correction for the potential small-sample bias, as pointed out by Gouriéroux, Renault, and Touzi (1995). We have experimented with indirect inference cor- 
rection, and we conclude that it does not make any significant improvement on the SPML estimator. The initial bias of the first step is so small that a correction would probably require such a large number of simulations that the indirect inference algorithm would become infeasible.

\section{Practical Implementation}

An important choice in the practical implementation of the SPMLE is the number of simulations, $S$. Our estimation algorithm was run with $S=500$. We chose this number since, after this point, changes in the estimated parameter vector due to simulation uncertainty were negligible. Our Monte Carlo experiment also suggests that this number of simulations is a reasonable choice.

Standard deviations of the SPML estimator were computed on the basis of this asymptotic result in $(A 3)$. The sample counterparts of $I_{0}$ and $J_{0}$ for the $2 \mathrm{~S}$ estimator are

$$
\begin{aligned}
& \hat{I}_{S T}=\frac{1}{T} \sum_{t=1}^{T}\left\{\frac{\partial \ell\left(Z_{t} ; \widetilde{X}_{t}, \widehat{\phi}_{S T}\right)}{\partial \phi} \frac{\partial \ell\left(Z_{t} ; \widetilde{X}_{t}, \widehat{\phi}_{S T}\right)}{\partial \phi^{\prime}}\right\} \\
& \hat{J}_{S T}=\frac{1}{T} \sum_{t=1}^{T}\left\{-\frac{\partial^{2} \ell\left(Z_{t} ; \widetilde{X}_{t}, \widehat{\phi}_{S T}\right)}{\partial \phi \partial \phi^{\prime}}\right\} .
\end{aligned}
$$

The main practical difficulty encountered in the estimation procedure was to pin down the variance of the latent state. In fact, when $\eta_{\omega}$ was estimated together with the other parameters, the algorithm would always tend to quickly increase the estimated variance generating an implausibly large high-frequency variability in the implied simulated paths of the wage premium and the labor share. Therefore, in the estimation, we restricted $\eta_{\omega}$ to belong to an interval for which the volatility of the model wage premium and the labor share are similar to their data counterpart.

With such a large parameter space and with simulation-based estimation techniques, there is uncertainty about whether the maximum found is local or global. To assess the global nature of the optimum, we used Veall (1990)'s test based on de Haan (1981)'s asymptotic confidence interval for the first-order statistics. Call $\hat{\ell}$ the value of the objective function at the optimum, and call $\ell^{1}$ and $\ell^{2}$ the highest two values of a vector of $M$ random evaluations of the likelihood in the parameter space. We reject the null hypothesis that the optimum is not a global maximum at the $(1-p)$ level of confidence if $\ell^{p}>\hat{\ell}$, where $\ell^{p}=\ell^{1}+\left(\ell^{1}-\ell^{2}\right) /\left(p^{\frac{-2}{k}}-1\right)$ and $k$ is the dimension of the parameter space. We performed $M=60,000$ random evaluations of the likelihood in the parameter space. ${ }^{31}$ We found that we could reject the null hypothesis only for $p=0.185$. Therefore, at a conventional 
confidence level (10 percent or 5 percent), the hypothesis is not rejected.

In addition, we used the information collected through these random evaluations for a further check. We identified among the $M$ evaluations those points far from our estimate of $\widehat{\phi}_{S T}$ where the likelihood was relatively high, and we restarted the maximization routine at those new initial guesses, but we found only lower local maxima. 


\section{Footnotes}

${ }^{1}$ Bound and Johnson (1992), among others, conclude that much of the variation in the skill premium is attributed to a residual trend component that is often called skill-biased technological change. These authors evaluate a number of explanations in the literature for the increase in wage inequality. Murphy and Welch (1992) emphasize the loss of high-wage manufacturing jobs associated with increased foreign competition and a higher trade deficit. Bluestone and Harrison (1988) stress the decline in the ability of labor unions to negotiate high wages.

2 The Gordon (1990) data cover the sample period until 1984. The computation of the stock of capital equipment and its relative price for the post-1983 period is described in detail in Appendix 2.

${ }^{3}$ Investment as a share of total output has remained roughly constant over the sample period. For more details on the index construction, see Appendix 1.

4 The ratio of skilled to unskilled labor input for other education-based skill definitions shows a similar trend. For example, if skilled labor is defined as requiring at least high school completion (12 years or more of education), the ratio of skilled to unskilled labor hours rises by a factor of more than six.

${ }^{5}$ See Greenwood, Hercowitz, and Krusell (1996) for details.

${ }^{6}$ Goldin and Katz (1995) analyze historical data on the premium to education for office workers and find that technological progress was a factor in increasing the demand for skill during the early parts of this century. Goldin and Katz (1995) document a decrease in the education premium and argue that it was mainly due to the increased supply of educated workers (high school graduates). Goldin and Katz (1996) qualitatively discuss the origins of capital-skill complementarity in terms of a three-factor production function that is a special case of one we consider. They conclude that long-run historical data support their specification. It is interesting to note that the specification advocated by Goldin and Katz on historical grounds is consistent with the preferred nesting of our model.

${ }^{7}$ Goldin and Katz (1996) have interpreted this general type of production function along the following lines. Production takes place in two stages: machine maintenance and assembly. In the first stage, skilled workers adopt new technologies and ensure that they work efficiently in the organization. In the second stage, assembly involves the product of machine maintenance and unskilled labor, and it is the more mechanical part of the production process. For illustration, Goldin and Katz (1996) suggest that machine maintenance is Leontief in skilled labor and total capital and that assembly is a Cobb-Douglas structure.

8 Note that this expression is an approximation, since we make use of the approximation $\ln (1+x) \simeq x$. As we discuss below, in the estimation of the model, we need to fix the scale, and we do this by restricting the initial value for the skilled labor efficiency. We are, therefore, free to select a value that makes the above expression very accurate.

${ }^{9} \mathrm{~A}$ steady-state growth path exists in this model either if $\rho=\sigma=0$ or if the long-run growth 
rates of all inputs in efficiency units are the same $\left(g_{u}=g_{s}=g_{k_{e}}\right)$. If these conditions are not satisfied, an asymptotic steady-state growth path exists, with either one or two factors having relatively little importance in the long run. Since we have abstracted from modeling household choices, our analysis does not have predictions for the long-run growth rates of these inputs.

10 Recall from the previous section the substantial difference in the growth rate of equipment relative to structures over this period.

11 For an estimation of the labor efficiency factors based on input share differences across sectors, see Kahn and Lim (1997).

${ }^{12}$ Neutral technological progress will not be treated as an additional latent state variable, but rather can be identified using our production function and measures of output. Output is taken to be the domestic product of the private sector, excluding the housing and the farm sectors.

${ }^{13}$ We have explored the implications of this assumption and found that it does not affect our results in any significant way. This is described in Subsection D.

${ }^{14}$ To simplify the analysis further, we assume that next period's realizations of neutral technological change $\left(A_{t+1}\right)$ and labor efficiency $\left(\psi_{t+1}\right)$ are known when investment decisions are made. Thus, the only uncertainty in this equation is that $q_{t+1}$ is unknown at date $t$. This information assumption simplifies the estimation of the model substantially, because it allows us to abstract from specifying a separate stochastic process for neutral technological change $\left(A_{t}\right)$. A specification that estimates the parameters of this process is much more complicated: it involves more parameters to be estimated, is computationally more intensive, and results in fewer degrees of freedom. Moreover, it requires an additional assumption of measurement error, since the output from the model under this specification will, in general, deviate from output in the data. For some of the model specifications, we estimated this more complicated version and found that the results changed in only minor ways. The main difference was that the estimation of this specification of the model was much slower.

${ }^{15}$ We specify an ARIMA model for forecasting the relative price of capital. This specification is detailed in Subsection D.

16 Since $\varepsilon_{t}$ enters in only the third equation, the first two elements of the vector are identically zero.

17 The parameter $\eta_{\varepsilon}$ is estimated as $\left(1-\delta_{e}\right)$ times the standard error of the residuals of a linear regression of $\frac{q_{t+1}}{q_{t}}$ on the variables in the information set $\xi_{t}$. The results are robust to different specifications of the conditional mean. The estimated equation is $\hat{q}_{t}=0.5-0.005 t+0.48 \hat{q}_{t-1}-$ $1.07 \varepsilon_{t-1}+\varepsilon_{t}$, where $\hat{q}_{t+1} \equiv \frac{q_{t+1}}{q_{t}}$, with $\bar{R}^{2}=0.49$ and $\hat{\sigma}_{\varepsilon}=0.023$.

18 By symmetry, the elasticity of substitution between unskilled labor and skilled labor is also 1.67. This estimate is near the benchmark value cited in Subsection A.

${ }^{19}$ Recall that our proxy condition for missing rental prices of structures and equipment equated the expected rate of return on investment to these two types of capital in our model, as opposed to the ex post returns shown in Figure 9.

${ }^{20}$ The large increase in the relative price is evident in both the official National Income and 
Product Accounts (NIPA) equipment price index and in Gordon's (1990) quality-adjusted data.

${ }^{21}$ In addition to the effect of a few influential observations, particularly the 17 percent return in 1974, other factors may account for the difference between the average returns on equipment and structures. In particular, equipment may yield a higher rate of return than structures, given that the volatility of equipment returns is so much higher. This outcome could occur if investors were risk averse.

22 We also used two-step SPMLE to estimate the parameters of the model. These estimates were similar to the OLS estimates.

${ }^{23}$ In conducting our analysis, we found that the difference between the trend growth rates of skilled and unskilled labor quality was important, rather than the absolute levels. Therefore, we normalize unskilled labor quality to have no trend growth in quality and, thus, estimate one less parameter. This reduced computation time significantly when we estimated versions of our model using the two-step SPMLE.

${ }^{24}$ We also estimated the parameters using the two-step SPMLE. The estimates were $\sigma=0.280$ and $\gamma_{s}-\gamma_{u}=0.090$.

${ }^{25} \mathrm{We}$ assessed the robustness of our results by considering two changes to our model. First, we used an alternative definition of skill, in which skilled workers were those with at least some college education (13 years of school or more). The basic findings were similar, with the elasticity of substitution between skilled labor and equipment very similar to that in the benchmark case and a moderately higher elasticity of substitution between unskilled labor and equipment (1.89 versus 1.67 in the benchmark model). Second, we assessed the sensitivity of our results to differential tax treatment of structures and equipment. There are two sources of differences in tax treatment: different depreciation allowances and the use of the investment tax credit (ITC), which applies only to equipment purchases. Cummins, Hassett, and Hubbard (1994) construct annual time series on the ITC and the present value of depreciation allowances for equipment and structures over the 1953-88 period. We incorporated the ITC into our analysis, but we could not use their data on depreciation allowances directly, since it would require us to keep track of the entire distribution of equipment and structures. Thus, a comprehensive analysis of tax differences across assets is beyond the scope of this paper. Adding the ITC to our analysis did not change the findings in any important way. The results were very similar to the benchmark model - the elasticities of substitution were nearly identical to those in the benchmark case. (The parameters were not strictly comparable to those reported in Subsection E, since the model with the ITC could be estimated only through 1988.) Given the tax benefit of the ITC, the average net ex post rate of return on equipment was about 3 percent higher than that on structures, versus 2 percent higher in the benchmark model. We concluded that explicitly accounting for the ITC would not materially change our findings.

26 No correction has been made for top-coded earnings. For instance, Juhn, Murphy, and Pierce (1993) impute earnings as 1.33 times the top-coded value, but they report that their results are not sensitive to this correction.

27 See, for instance, Triplett (1992) or Berndt, Griliches, and Rappaport (1995). The latter 
paper reports that the price index based on the matching models procedure largely underestimates the decline in the price of $\mathrm{PCs}_{\mathrm{s}}$ - compared with hedonic price methods.

${ }^{28}$ It is a composite index of seven lagged indicators, named DLAGG in the Citibase data set.

29 See Statistical Abstract of the United States (1991, Tables 1273, 1274, 1277, pp. 754-55) and Statistical Abstract of the United States (1992, Tables 1256 and 1258, p. 771) for the share of different types of computers, the share of peripherals, and the fraction sold to business.

30 See Berndt, Griliches, and Rappaport (1995), footnote 2, p. 245.

31 It is not immediately obvious what the optimal ratio $M / k$ should be. Veall (1990) finds that in some cases with 3 parameters, 10 random draws would deliver satisfactory results in terms of test power, but other examples with only 1 parameter needed at least 200 draws. 


\section{References}

Berndt, E. R. and Christensen, L. R. 1974. Testing for the Existence of an Aggregate Index of Labor Inputs. American Economic Review, 64(3), 391-404.

Berndt, E. R., Griliches, Z., and Rappaport, N. J. 1995. Econometric Estimates of Price Indexes for Personal Computers in the 1990's. Journal of Econometrics, 68(1), 243-68.

Bluestone, B. and Harrison, B. 1988. The Growth of Low-Wage Employment: 1963-86. American Economic Review, 78(2), 124-28.

Bound, J. and Johnson, G. 1992. Changes in the Structure of Wages in the 1980's: An Evaluation of Alternative Explanations. American Economic Review, 82(3), 371-92.

Brown, K. and Greenstein, S. M. 1995. How Much Better is Bigger, Faster \& Cheaper? Buyer Benefits from Innovation in Mainframe Computers in the 1980s. Working Paper 5138, National Bureau of Economic Research.

Brown, R. and Christensen, L. 1981. Estimating Elasticities of Substitution in a Model of Partial Static Equilibrium: An Application to U.S. Agriculture, 1947-74. In Berndt, E. and Field, B. (Eds.), Modeling and Measuring Natural Resource Substitution. MIT Press, Cambridge, MA.

Cole, R., Chen, Y., Barquin-Stolleman, J., Dulberger, E., Helvacian, N., and Hodge, J. 1986. Quality-Adjusted Price Indexes for Computer Processors and Selected Peripherals Equipment. Survey of Current Business, January.

Cooley, T. F. 1995. Frontiers of Business Cycle Research. Princeton, N. J.: Princeton University Press.

Cummins, J. G., Hassett, K. A., and Hubbard, R. G. 1994. A Reconsideration of Investment Behavior Using Tax Reforms as Natural Experiments. Brookings Papers on Economic Activity, 2, 1-59.

de Haan, L. 1981. Estimation of the Minimum of a Function Using Order Statistics. Journal of the American Statistical Association, 76(374), 467-69.

Denny, M. and Fuss, M. A. 1977. The Use of Approximation Analysis to Test for Separability and the Existence of Consistent Aggregates. American Economic Review, 67(3), 404-18.

Fallon, P. R. and Layard, P. R. G. 1975. Capital-Skill Complementarity, Income Distribution, and Output Accounting. Journal of Political Economy, 83(2), 279-301.

Goldin, C. and Katz, L. F. 1995. The Decline of Non-Competing Groups: Changes in the Premium to Education, 1890 to 1940. Working Paper 5202, National Bureau of Economic Research.

Goldin, C. and Katz, L. F. 1996. The Origins of Capital-Skill Complementarity. Mimeo, Harvard University.

Gordon, R. J. 1990. The Measurement of Durable Goods Prices. National Bureau of Economic Research Monograph Series, Chicago: University of Chicago Press.

Gouriéroux, C., Monfort, A., and Trognon, A. 1984. Pseudo Maximum Likelihood Methods: Theory. Econometrica, 52(3), 681-700. 
Gouriéroux, C., Renault, E., and Touzi, N. 1995. Calibration by Simulation for a Small Sample Bias Correction. Manuscript.

Greenwood, J., Hercowitz, Z., and Krusell, P. 1996. Long-Run Implications of Investment-Specific Technological Change. Forthcoming in American Economic Review.

Griliches, Z. 1969. Capital-Skill Complementarity. Review of Economics and Statistics, 51(4), 465-68.

Hamermesh, D. S. 1993. Labor Demand. Princeton, N. J.: Princeton University Press.

Johnson, G. E. 1997. Changes in Earnings Inequality: The Role of Demand Shifts. Journal of Economic Perspectives, 11(2), 41-55.

Juhn, C., Murphy, K. M., and Pierce, B. 1993. Wage Inequality and the Rise in Returns to Skill. Journal of Political Economy, $101(3), 410-442$.

Kahn, J. and Lim, J.-S. 1997. Skilled Labor-Augmenting Technical Progress in U.S. Manufacturing. RCER Working Paper 437.

Katz, L. F. and Murphy, K. M. 1992. Changes in Relative Wages, 1963-1987: Supply and Demand Factors. Quarterly Journal of Economics, 107(1), 35-78.

Laroque, G. and Salanié, B. 1989. Estimation of Multi-Market Fix-Price Models: An Application of Pseudo Maximum Likelihood Methods. Econometrica, 57(4), 831-60.

Laroque, G. and Salanié, B. 1993. Simulation Based Estimation of Models with Lagged Latent Variables. Journal of Applied Econometrics, 8(0), 119-133.

Laroque, G. and Salanié, B. 1994. Estimating the Canonical Disequilibrium Model: Asymptotic Theory and Finite Sample Properties. Journal of Econometrics, 62(2), 165-210.

Murphy, K. M. and Welch, F. 1992. The Structure of Wages. Quarterly Journal of Economics, $107(1), 285-326$.

Ohanian, L., Violante, G., Krusell, P., and Ríos-Rull, J.-V. 1996. Simulation-Based Estimation of a Nonlinear Latent Factor Aggregate Production Function. Forthcoming in Simulation-Based Inference in Econometrics: Theory and Applications (edited by R. S. Mariano, T. Schuermann, and M. Weeks). Cambridge: Cambridge University Press.

Prescott, E. C. 1986. Theory Ahead of Business Cycle Measurement. Carnegie-Rochester Conference Series on Public Policy, 25(0), 11-44. Also in Federal Reserve Bank of Minneapolis Quarterly Review, 10 (4), 9-22.

Rosen, S. 1968. Short-Run Employment Variation on Class-I Railroads in the U.S., 1947-1963. Econometrica, 36(3-4), 511-29.

Stokey, N. L. 1996. Free Trade, Factor Returns, and Factor Accumulation. Journal of Economic Growth, 1(4), 421-47.

Triplett, J. E. 1992. Economic Theory and BEA's Alternative Quantity and Price Indexes. Survey of Current Business, 72(4), 49-52. 
Veall, M. R. 1990. Testing for a Global Maximum in an Econometric Context. Econometrica, 58(6), 1459-65.

White, H. 1982. Maximum Likelihood Estimation of Misspecified Models. Econometrica, 50(1), $1-25$.

White, H. 1994. Estimation, Inference and Specification Analysis. Cambridge: Cambridge University Press. 


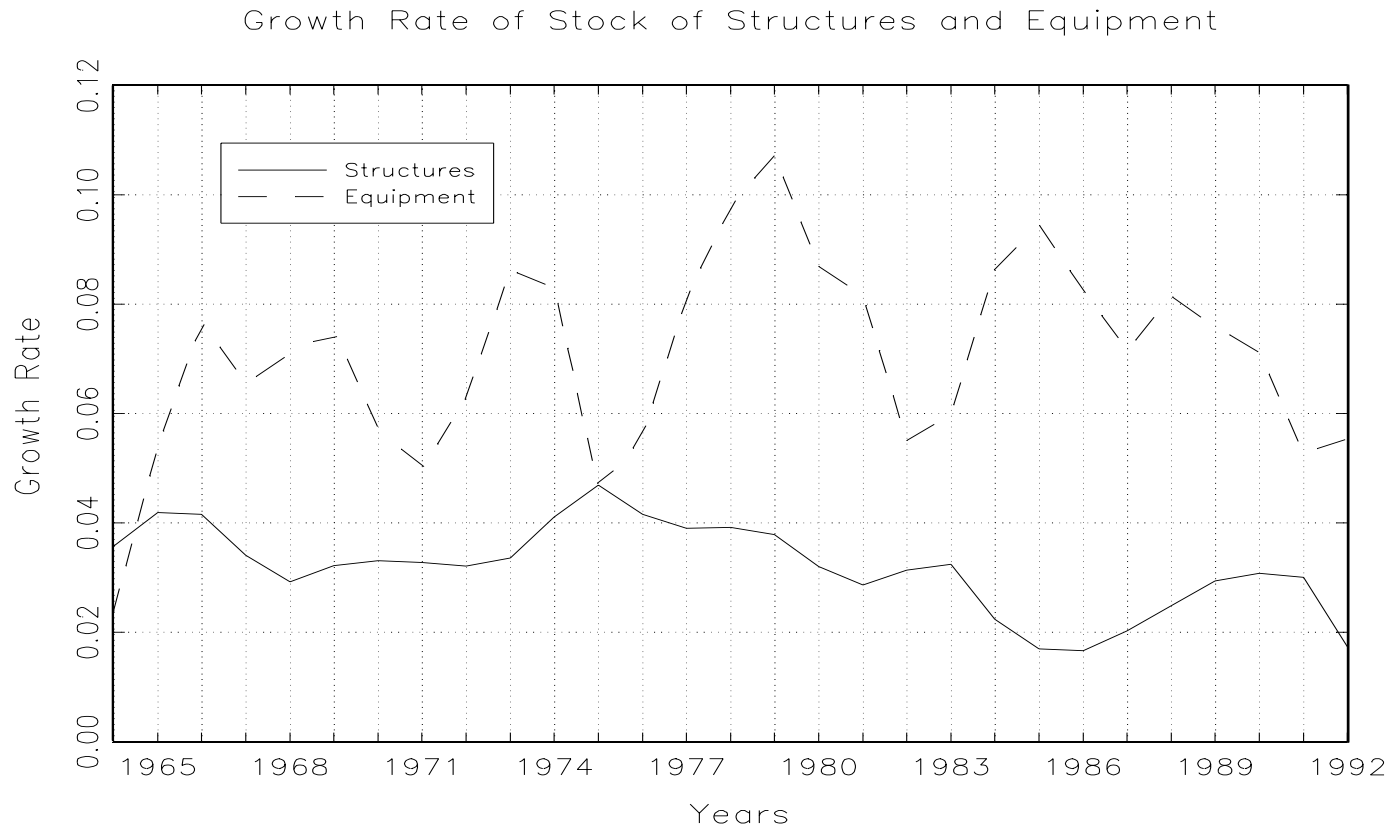

Figure 1: Growth Rates of Structures and Equipment 
Tue Mor 5 22:57:16 1996

Relative Price of Equipment

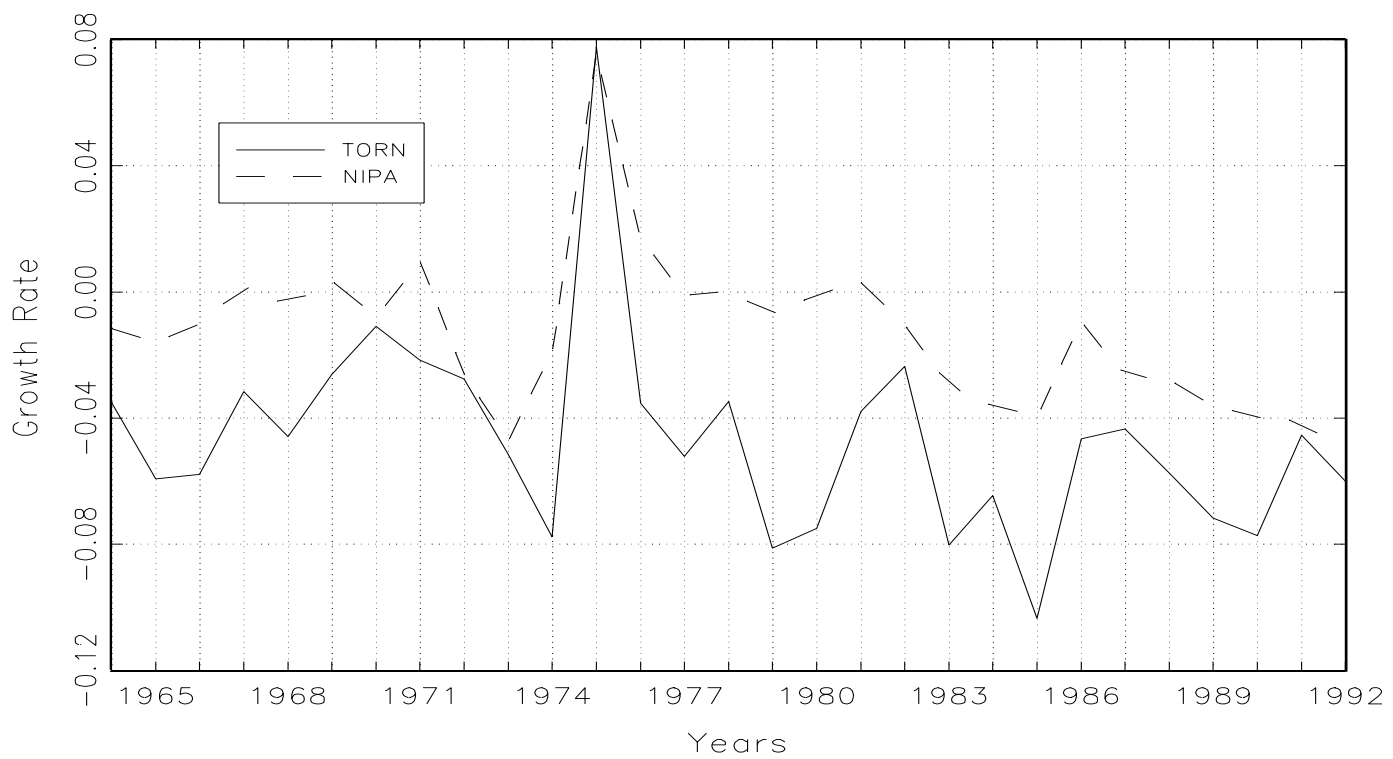

Figure 2: Relative Price of Equipment 


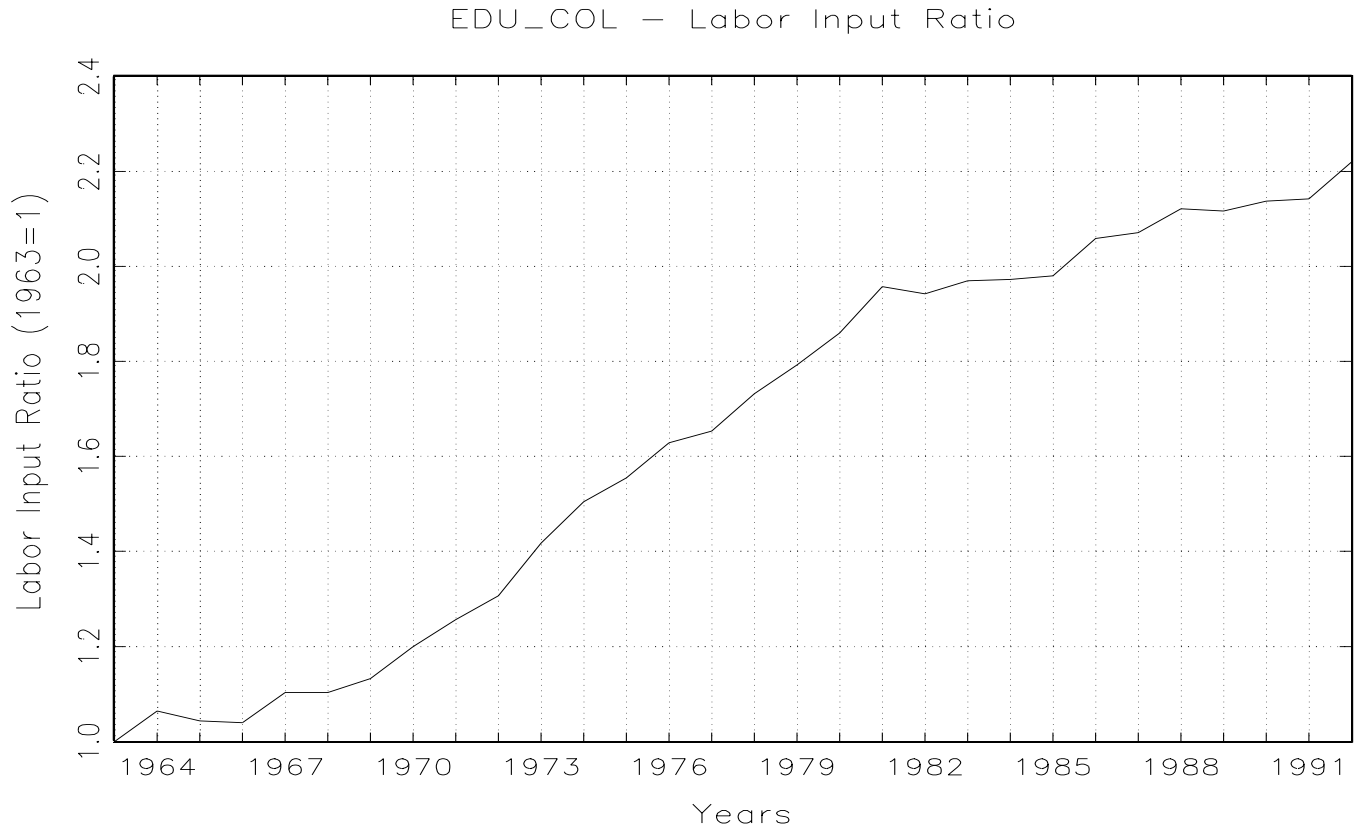

Figure 3: Evolution of the Relative Quantity of Labor (Skilled Labor Requires College Completion) 


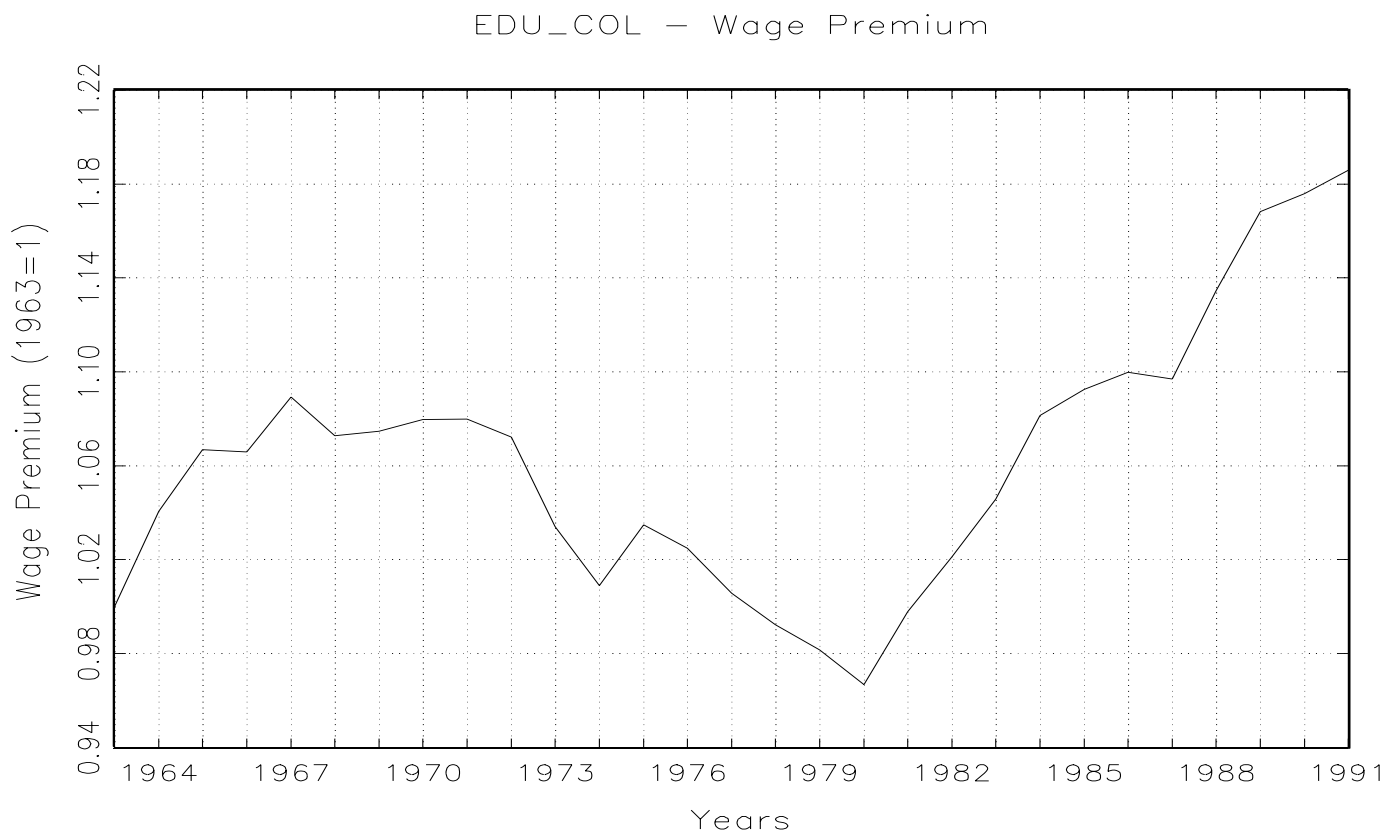

Figure 4: Evolution of the Skill Premium (Skilled Labor Requires College Completion) 


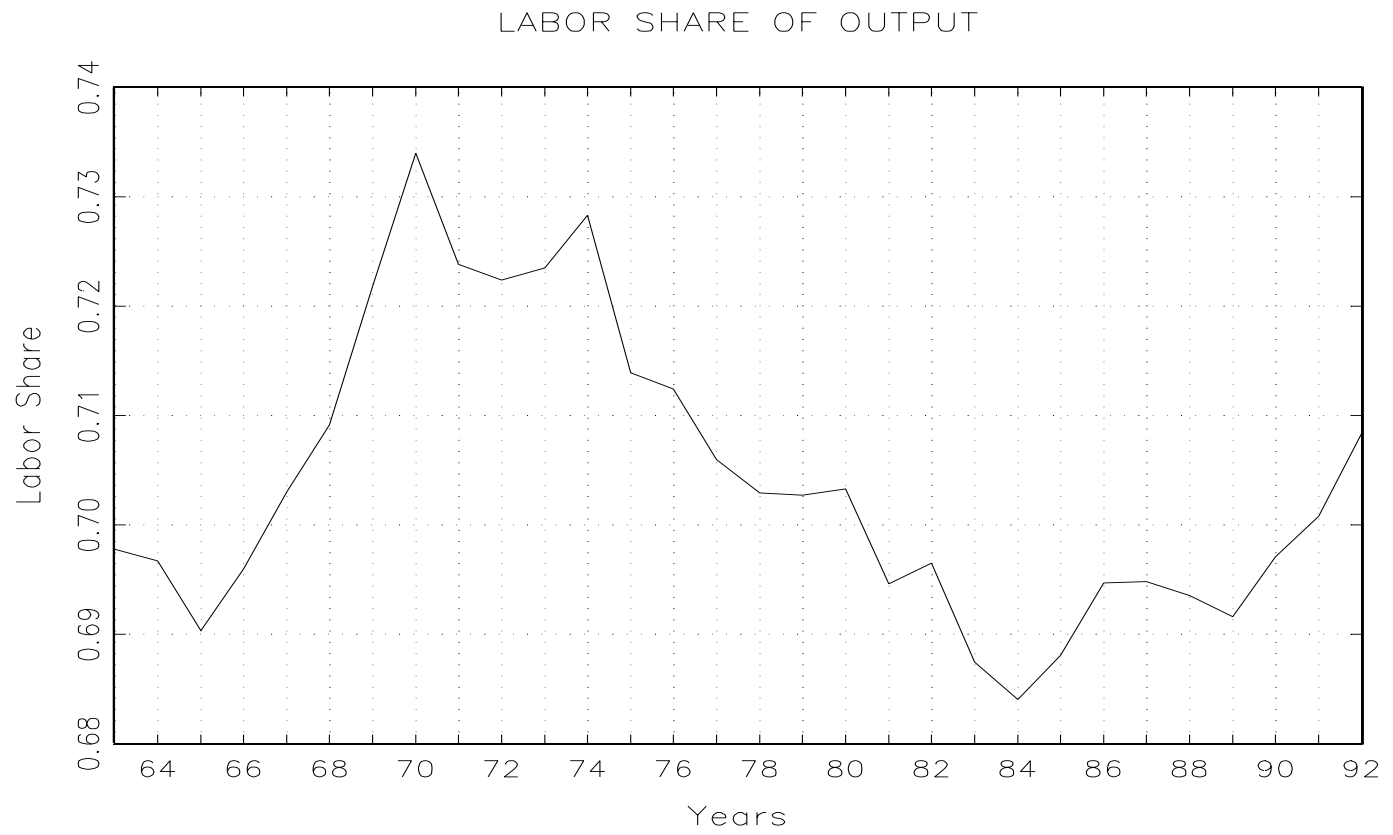

Figure 5: Evolution of Labor Share of Output 


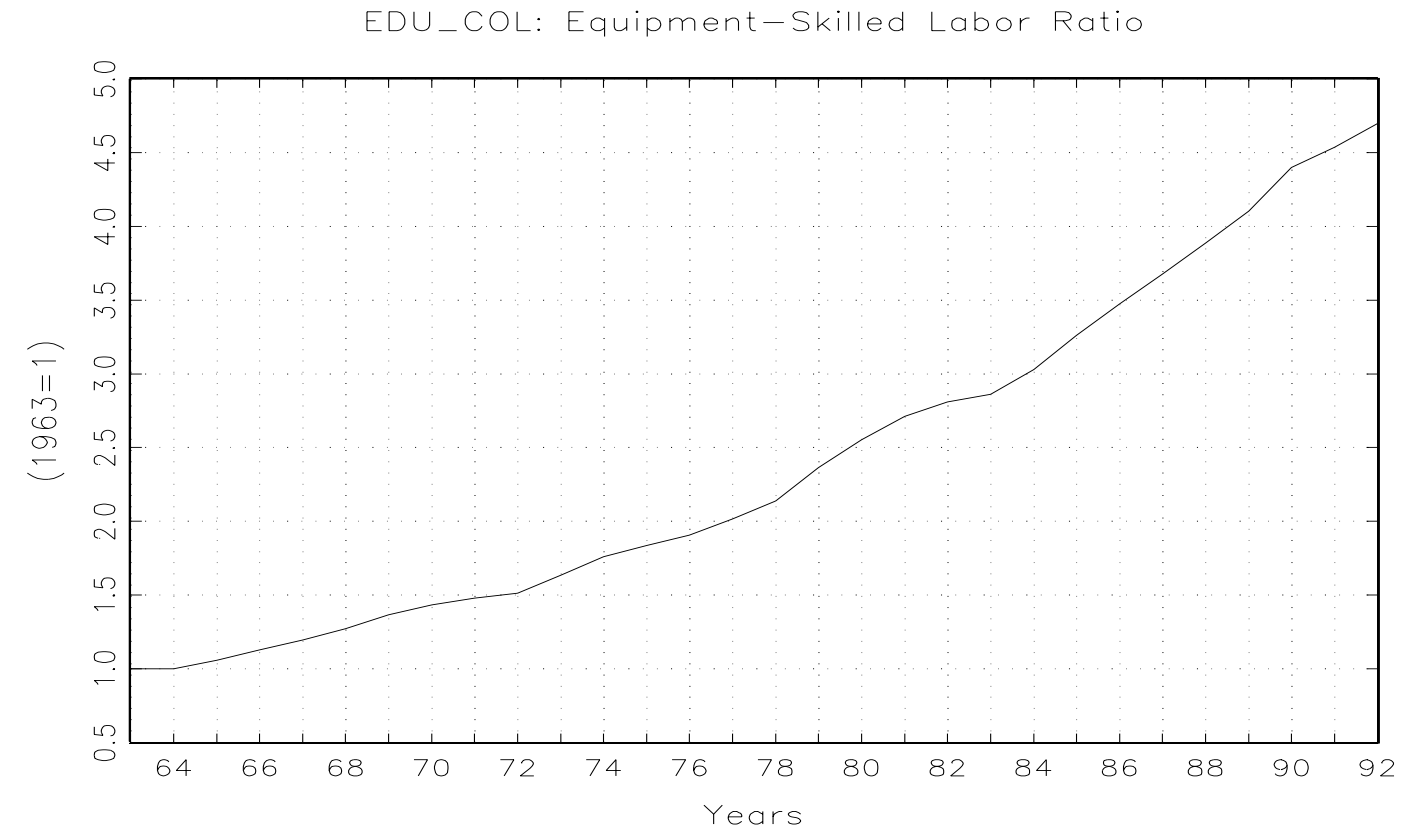

Figure 6: Ratio of Equipment to Skilled Labor Input (College Completion) 


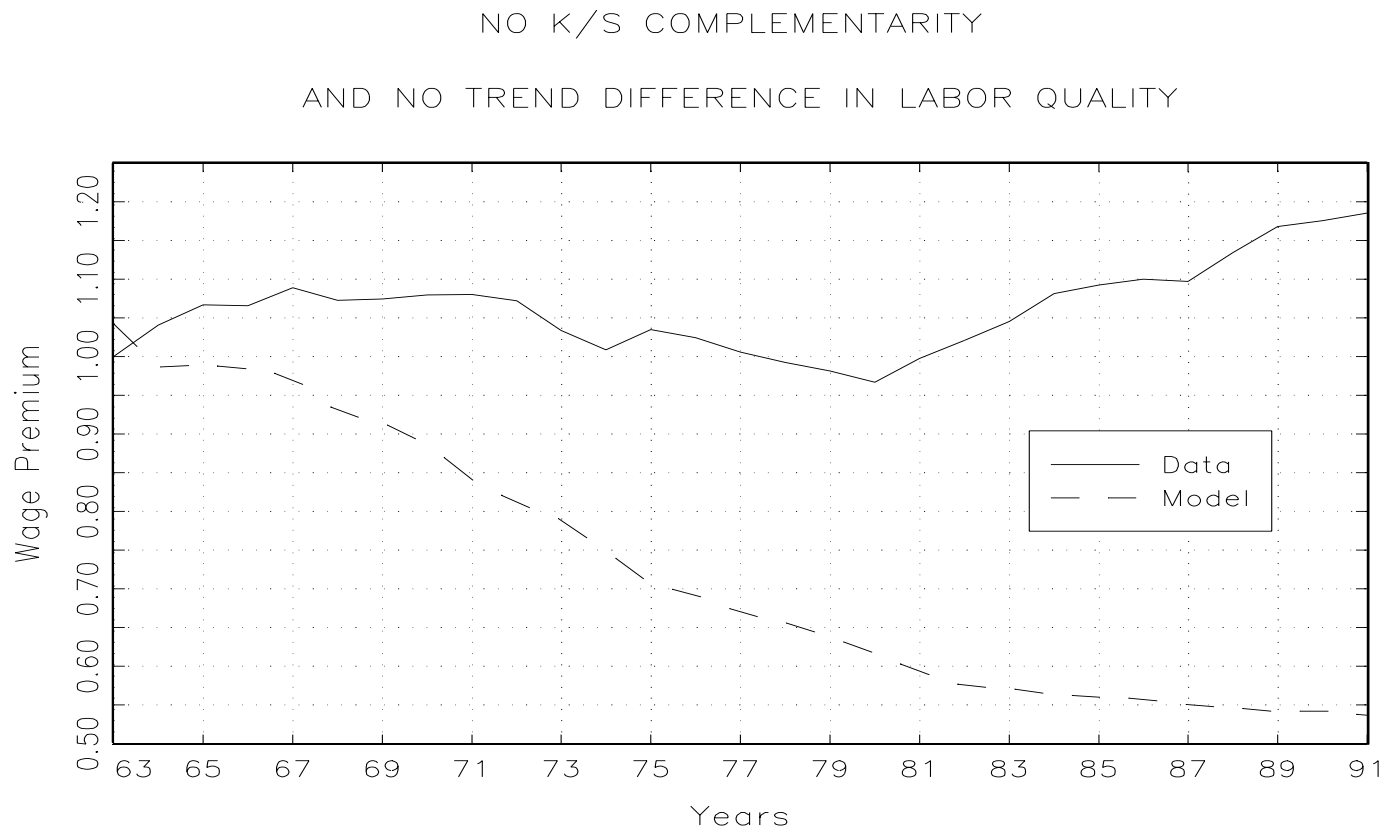

Figure 7: Skill Premium: No Capital-Skill Complementarity 


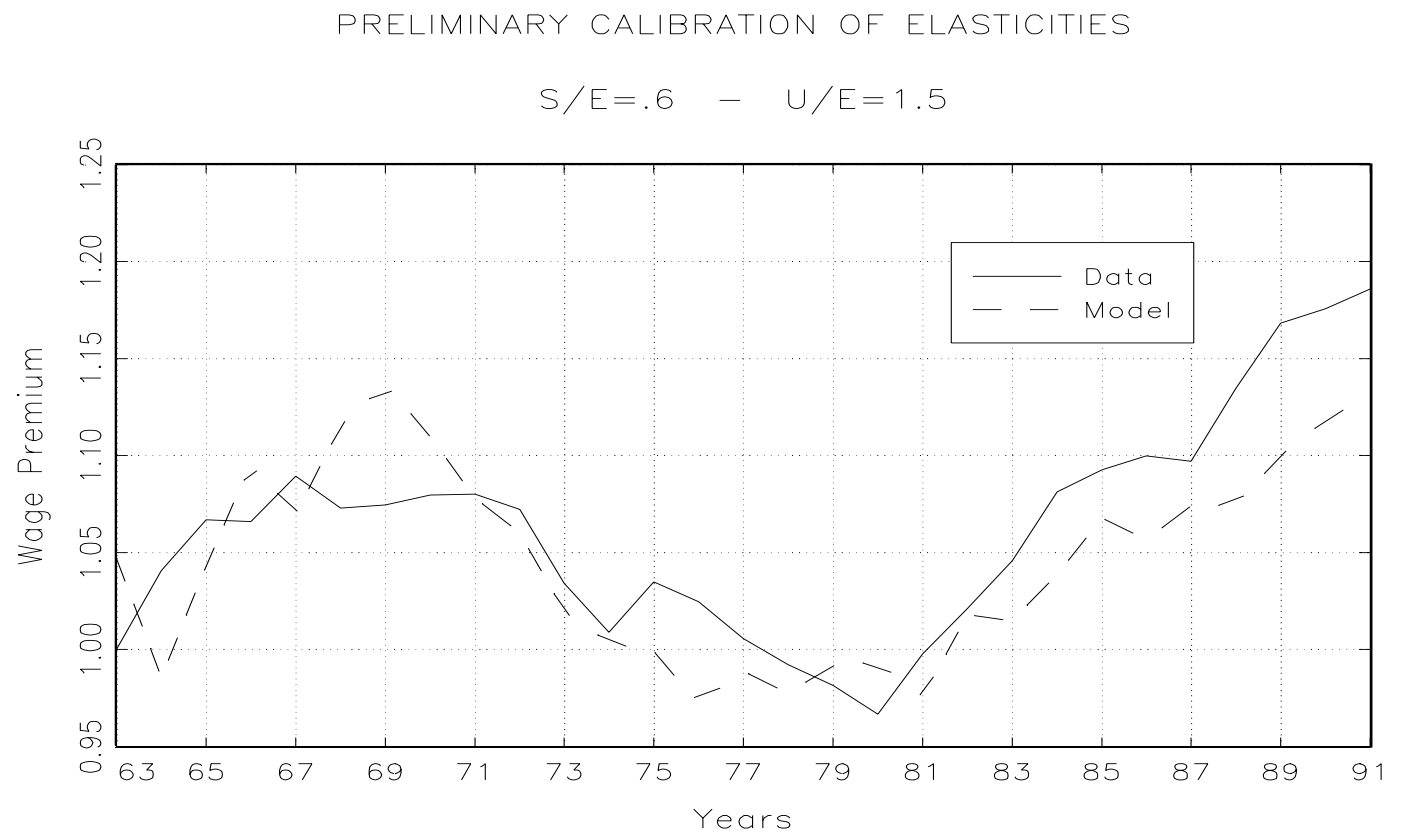

Figure 8: Skill Premium: Moderate Capital-Skill Complementarity 

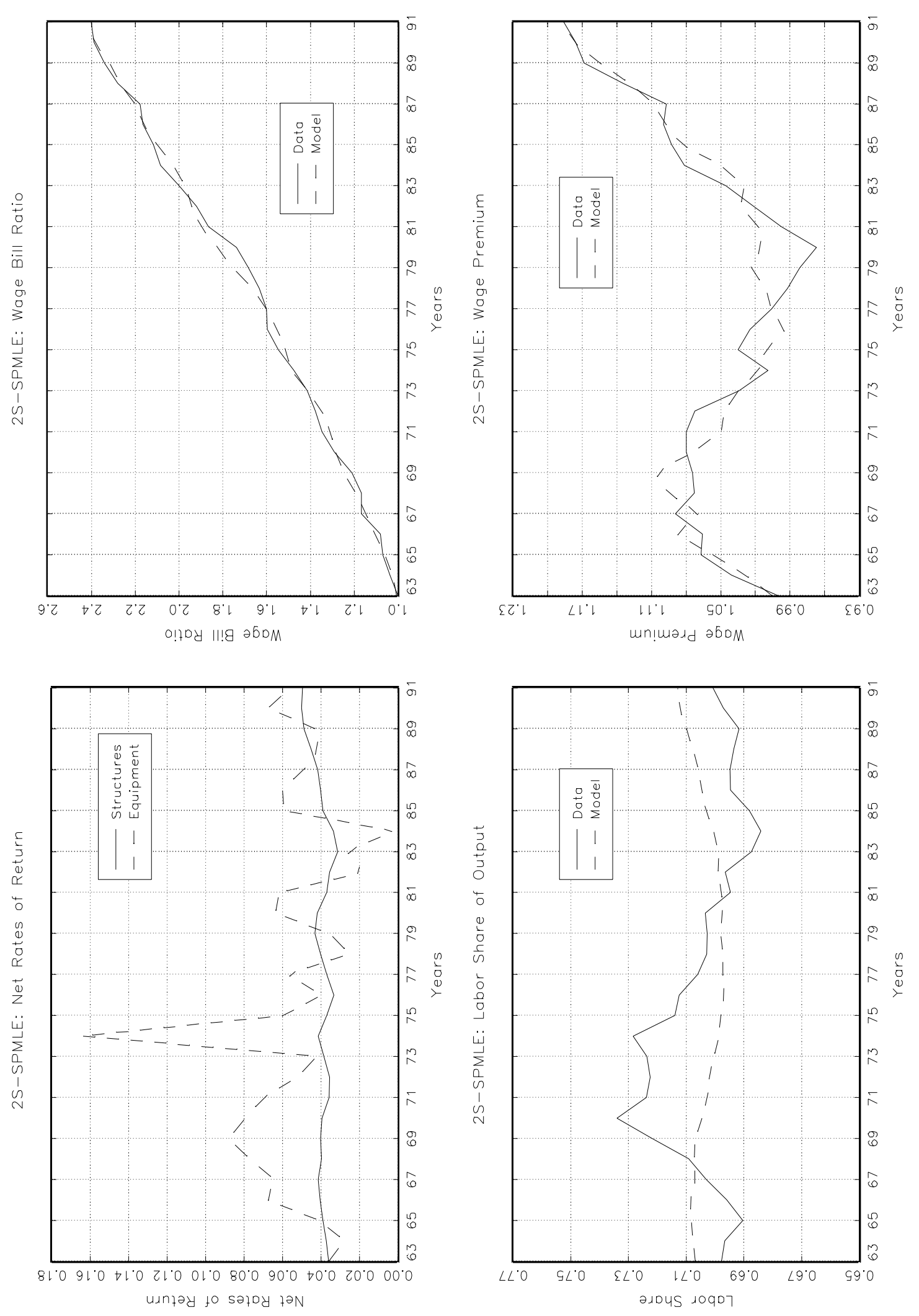

Figure 9: Behavior of the Benchmark Model (Estimated Parameters) and the Data 

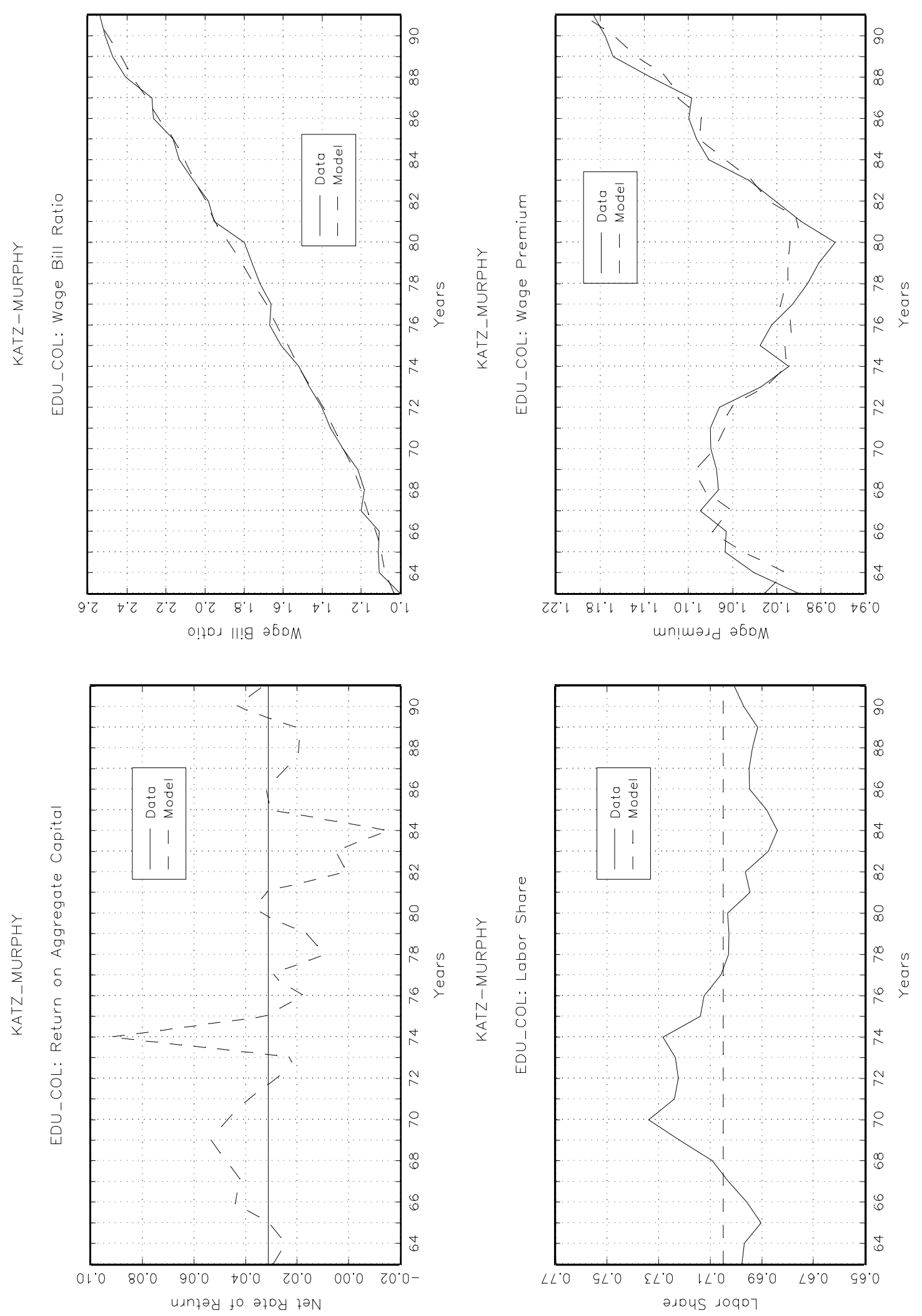

Figure 10: Behavior of the Katz-Murphy type Model (Estimated Parameters) and the Data 

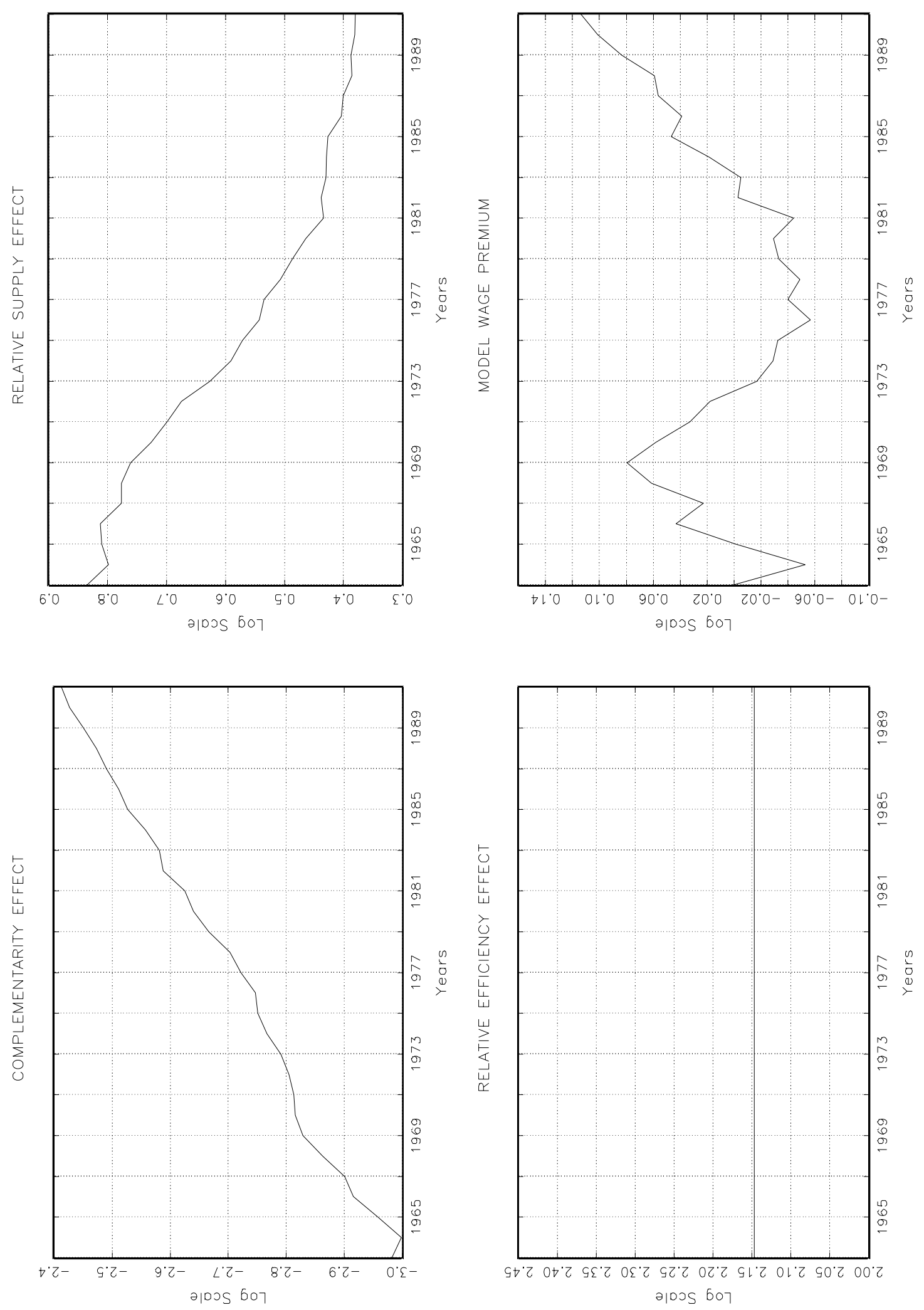

Figure 11: Decomposition of the Influence of Different Factors on the Skill Premium 
Thu Nov 30 17:45:04 1995

Nominal Shares of Investment in Equipment

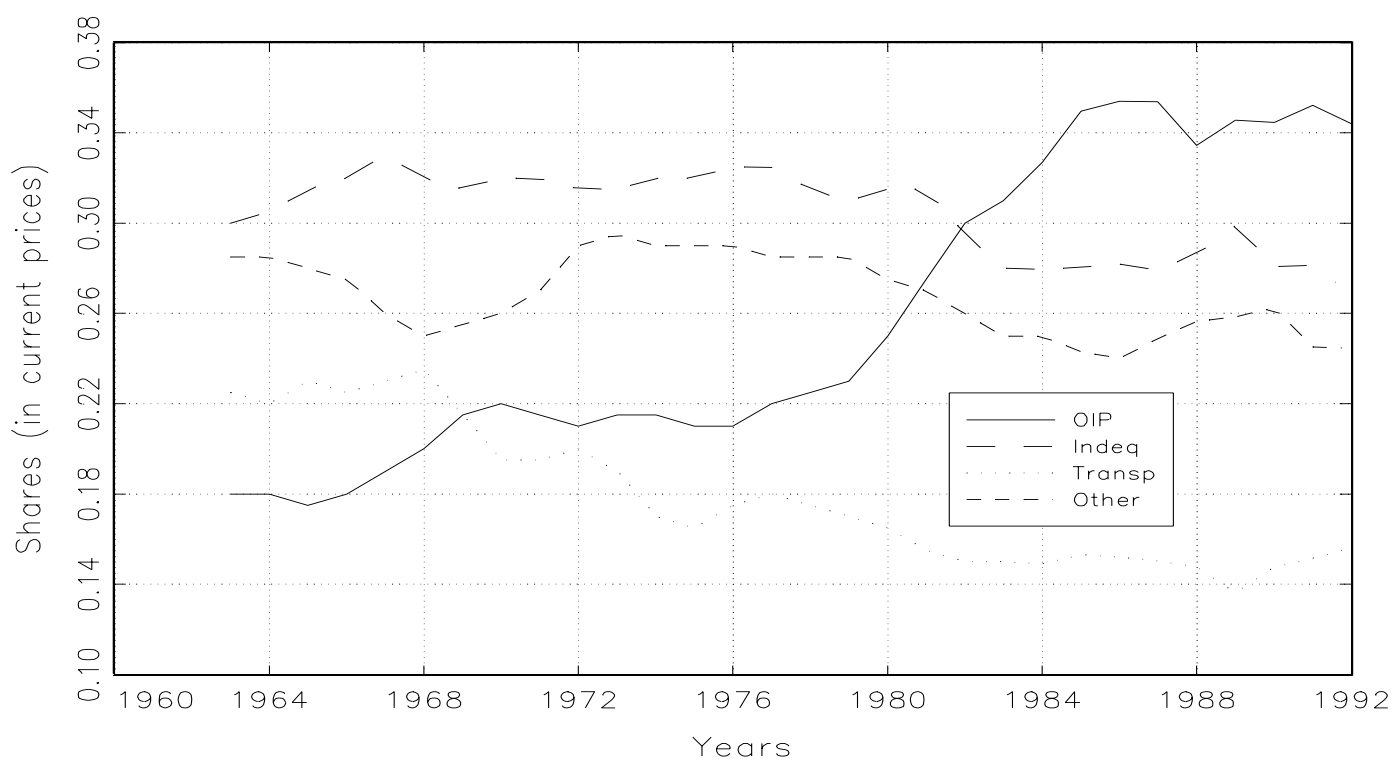

Figure 12: Nominal Shares of the Four Main Categories of Investment in Equipment 


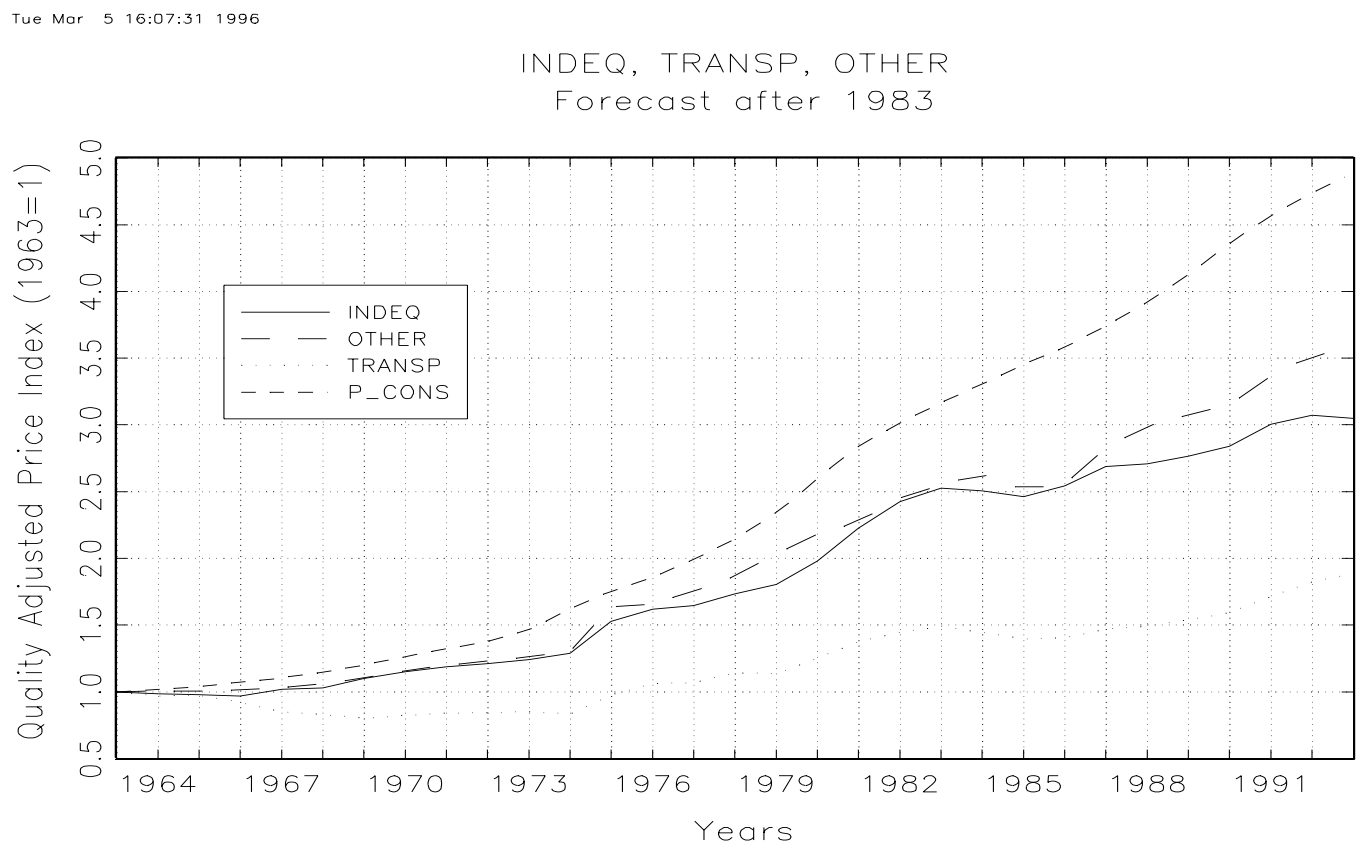

Figure 13: Quality-Adjusted Price Indices (Forecasts After 1983) for Various Equipment Components 


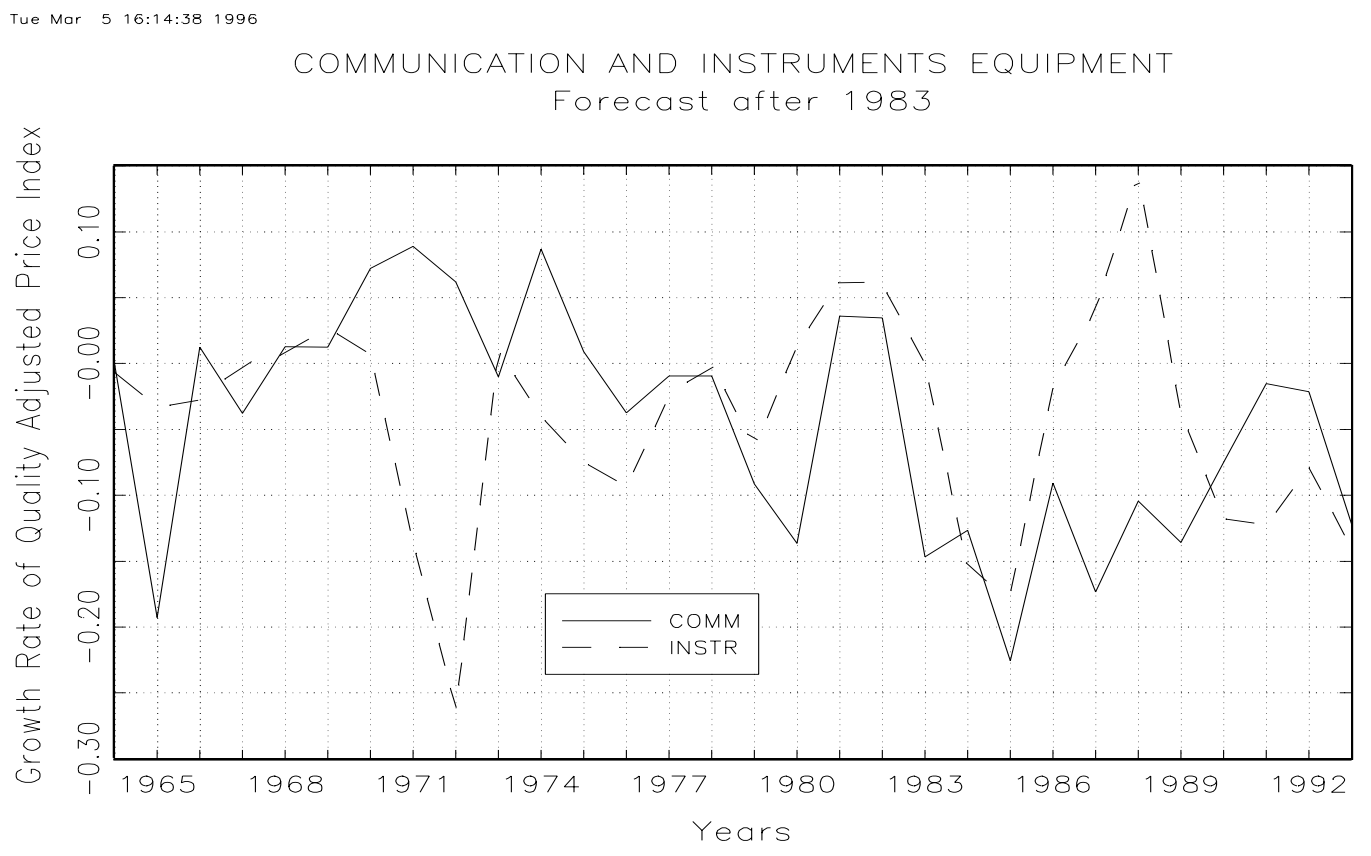

Figure 14: Growth Rate of the Price Index of Communication and Instrument Equipment (Forecasts After 1983) 


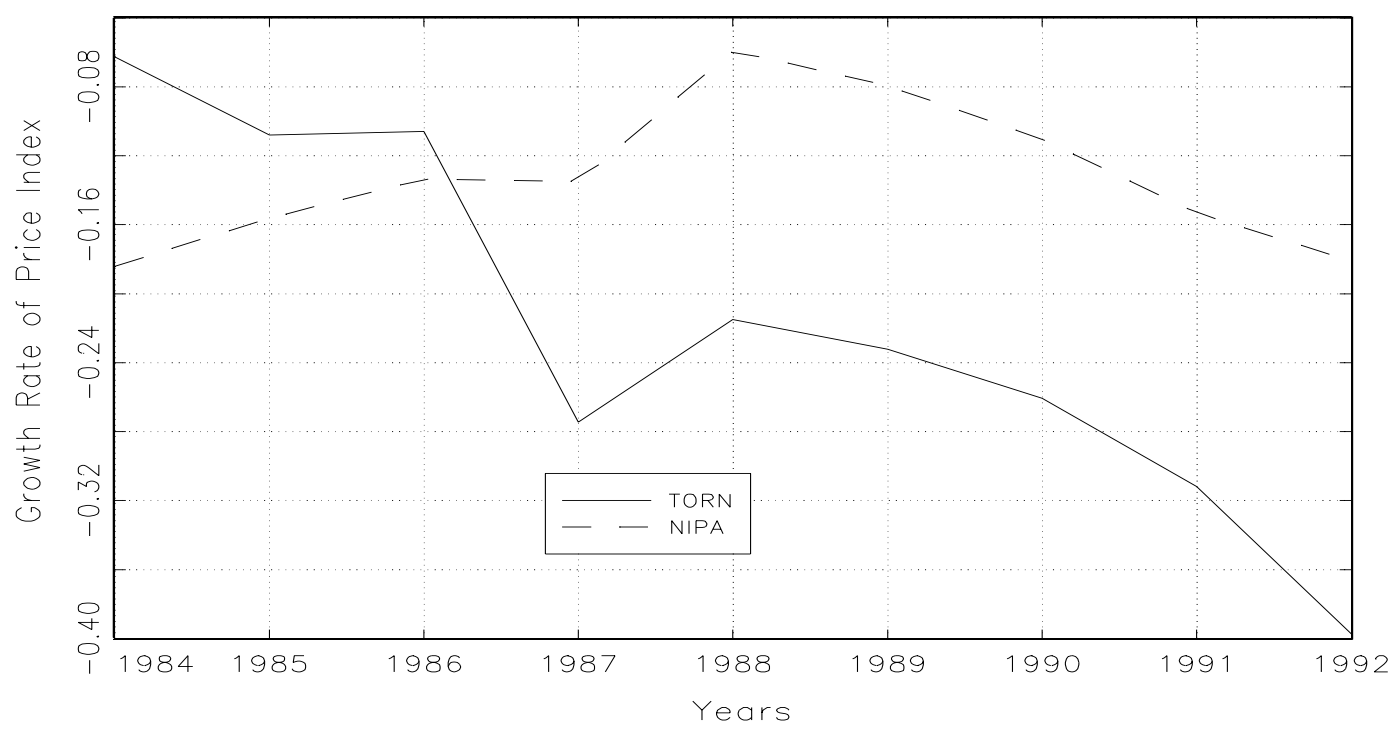

Figure 15: Growth Rate of the Price Index of Computers and Peripherals 


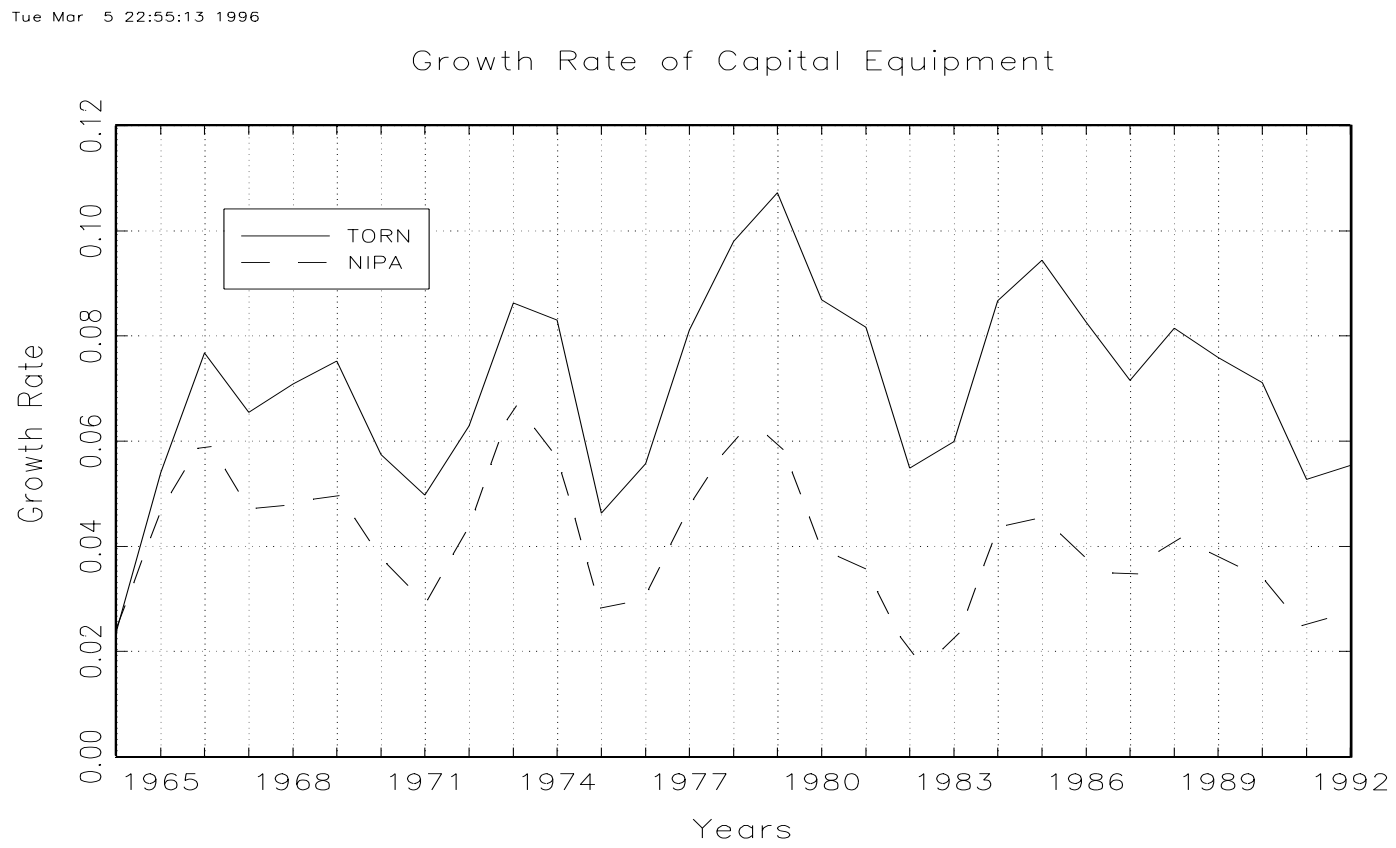

Figure 16: Growth Rate of Equipment With the NIPA and Our Extension of Gordon's (1990) Price Indices 